This item was submitted to Loughborough's Research Repository by the author.

Items in Figshare are protected by copyright, with all rights reserved, unless otherwise indicated.

\title{
Constitutive model for fibre reinforced concrete based on the Barcelona test
}

PLEASE CITE THE PUBLISHED VERSION

https://doi.org/10.1016/j.cemconcomp.2014.07.017

\section{PUBLISHER}

(c) Elsevier

VERSION

AM (Accepted Manuscript)

\section{PUBLISHER STATEMENT}

This work is made available according to the conditions of the Creative Commons Attribution-NonCommercialNoDerivatives 4.0 International (CC BY-NC-ND 4.0) licence. Full details of this licence are available at: https://creativecommons.org/licenses/by-nc-nd/4.0/

\section{LICENCE}

CC BY-NC-ND 4.0

\section{REPOSITORY RECORD}

Blanco, Ana, Pablo Pujadas, Sergio H. Cavalaro, Albert De la Fuente, and Antonio Aguado. 2019. "Constitutive Model for Fibre Reinforced Concrete Based on the Barcelona Test". figshare. https://hdl.handle.net/2134/32305. 


\title{
Constitutive model for fibre reinforced concrete based on the Barcelona test
}

\author{
Ana Blanco ${ }^{*}$, Pablo Pujadas a, Sergio Cavalaroa, Albert de la Fuentea, Antonio Aguado ${ }^{a}$ \\ a Department of Construction Engineering, Universitat Politècnica de Catalunya, UPC, Jordi Girona 1-3, 08034 \\ Barcelona, Spain. \\ * Corresponding author. Tel.: +34-93-401-7347; fax: +34-93-401-1036; e-mail: ana.blanco@upc.edu
}

\begin{abstract}
Several constitutive models for fibre reinforced concrete (FRC) have been reported in the past years based on the flexural performance obtained in a bending test. The Barcelona test was presented as an alternative to characterize the tensile properties of FRC; however, no constitutive model was derived from it. In this article, a formulation to predict the tensile behaviour of FRC is developed based on the results of the Barcelona test. The constitutive model proposed is validated by simulating the results of an experimental program involving different types of fibres and fibre contents by means of finite element software. Moreover, the simplified formulation proposed is compared with constitutive models from European codes and guidelines.
\end{abstract}

Keywords: Fibre Reinforced Concrete; Constitutive Model; Barcelona Test; Modelling; Design

\section{Introduction}

The design codes and guidelines for fibre reinforced concrete (FRC) propose different constitutive models that share a common approach: the parameters that determine the tensile behaviour are retrieved from the results of flexural tests on beams [1]. The setup and load configuration adopted produce a gradual evolution of energy release during the loading procedure, which simplifies the control and the assessment of the response of the material depending of the level of damage. Moreover, an isostatic configuration is used, meaning that the internal forces may be easily derived. As an indirect consequence, the beam test has become the reference for the systematic quality control of FRC.

Nevertheless, despite these advantages, the method also shows drawbacks. On one hand, some authors suggest that the shape and size of the specimen and its production process favours a preferential alignment of the fibres along the axis of the beam [2]. This tends to increases the mechanical efficiency and the overall tensile response of the FRC, which might not occur in the case of full-scale structures without a marked preferential orientation [3-6]. On the other hand, the small area of the beam subjected to cracking reduces the total amount of non-elastic energy mobilised and contributes to increase the scatter in the results [7, 8]. In addition to that, the weight of the specimen and the type of equipment required complicate the test procedure and limit the number of elements characterized per batch. This leads to a serious contradiction in terms of the quality control of FRC since it is essential to characterize a minimum number of elements in order to obtain reliable tensile strength values, especially in a materials affected by a high scatter.

Alternative tests have been proposed with the aim of reducing this favourable orientation and the scatter. This is the case of the round panel and the EFNARC panel tests. Although both of them seem to overcome the issues mentioned, the size of the specimen required increases the setup complexity, thus limiting even more the number of results obtained per batch. In this context, the Barcelona test [8,9] according to UNE 83515:2010 [10] has been proposed as an intermediate alternative between the beam and the panel tests. Even though it might show some disadvantages regarding the control of crack initiation and the estimation of the internal stress distribution, it is simpler to perform, less-time demanding and more sustainable than other methods in terms of volume of concrte consumed [8, 11-12]. Furthermore, since a bigger cracked surface is mobilized, it yields values of the residual tensile strength and toughness with an average coefficient of variation that are usually below those of the beam test [8]. Such evidences suggest that the Barcelona test 
might be an adequate option for the systematic quality control of FRC. However, its acceptance in practice is still hindered by the absence of simplified formulation to derive the tensile constitutive models from the test results.

The objective of this paper is to propose an analytical formulation for the estimation of the tensile constitutive curve of the FRC directly from the results of the Barcelona test. For that, an analytical deduction is performed considering the changes in the resistant mechanism experienced by the specimen during the test procedure. Then, the formulation obtained is validated through a FEM back analysis using results of tests conducted in laboratory with concrete reinforced with steel and plastic fibres. Finally, the constitutive equations derived from the Barcelona test and from the beam test for the same concrete are compared. The results obtained confirm the validity of the formulation proposed in this paper, thus representing a contribution towards the reliable and simple characterisation of the material.

\section{Description of the Barcelona test}

The Barcelona test is a double punch test (DPT) performed on a cylindrical FRC specimen with a diameter and a height of $150 \mathrm{~mm}$, according to the specifications in the Spanish standard UNE 83515 [10]. Cylindrical steel punches with a height of $24 \mathrm{~mm}$ and a diameter of $37.5 \mathrm{~mm}$ are placed at the centre of the top and the bottom surfaces of the specimen. As shown in Figure 1a, an extensometer chain is placed at half-height of the specimen to measure the Total Circumferential Opening Displacement (TCOD) experienced. A constant relative displacement rate of $0.5 \pm 0.05 \mathrm{~mm}$ is applied by the piston of the press. The force and the TCOD are also measured.
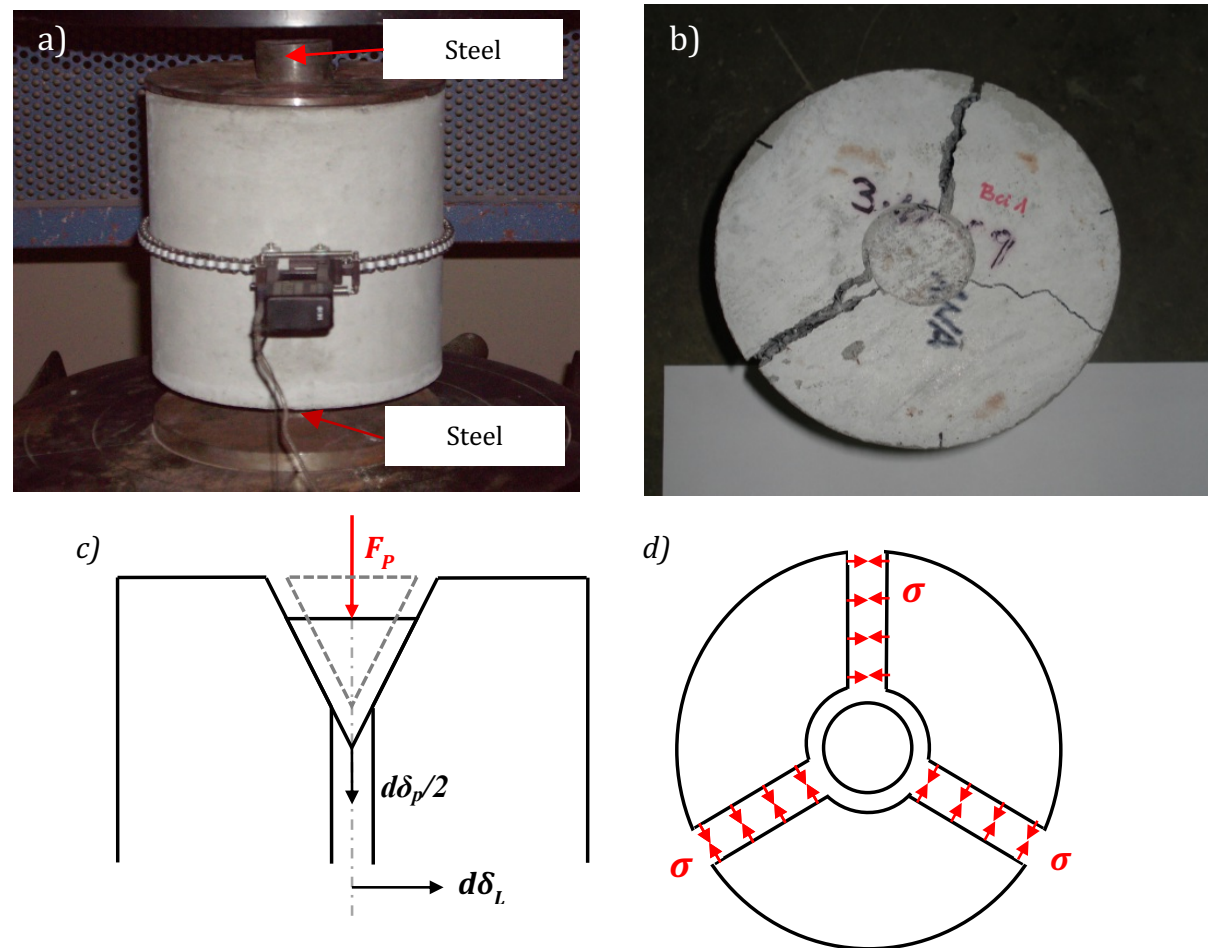

Figure 1. a) Barcelona test setup, b) top view of the specimen after the test, c) frontal view of the specimen after cracking and d) top view of the specimen after cracking.

Recent studies have shown that it is possible to estimate the TCOD without the need of using the extensometer chain. Carmona et al. [12] proposed an experimental correlation between the axial displacement and the TCOD. Subsequently, Pujadas et al. [13] presented an analytical correlation that is valid for the whole extent of the curve and for any type of FRC. The same authors have also 
demonstrated that the test may be conducted with cubic specimens with $150 \mathrm{~m}$ of side without the extensometer chain [14].

During the test, the applied load produces a tensile stress field inside the specimen. In this first stage, the concrete matrix is responsible for bearing the stresses. When the tensile strength of concrete is reached, a transition stage occurs: between 2 to 4 radial cracks are abruptly formed perpendicular to the stress field (see Figure $1 \mathrm{~b}$ ) and two wedges are formed under the cylindrical punches where the load is applied. These wedges may be idealized as cones with the same diameter of the punches $[9,10,12,15,16]$. In this moment, part of the elastic energy is released and a change in the resistant mechanism is observed since the fibres become active; being responsible for bearing the tensile stresses at a sectional level (see Figure 1c). Once the cracks have appeared, the specimen enters a kinematic stage, in which the conical wedges slide into the specimen with a certain displacement $\left(\delta_{p}\right)$ causing the lateral displacement $\left(\delta_{L}\right)$ of the concrete segments and the corresponding crack opening (see Figures $1 \mathrm{c}$ and $1 \mathrm{~d}$ ). Further detail on the failure mechanism may be found in [13].

Differences in the fracture of the specimens help to explain the particularities in the results from the Barcelona test and the flexural test. Notice that the total cracked surface in the former is up to 2.2 times that of the latter. Consequently, the total non-elastic energy mobilized in the Barcelona test will be higher, favouring smaller scatter in the post-cracking results.

In the Barcelona test, the biggest part of the elastic energy is released abruptly at the moment of cracking and a remaining small part is released during the post cracking stage. On the contrary, in the flexural test, the release occurs at a much slower rate during almost the whole post cracking stage since the crack depth increases gradually. On one hand, this may be an advantage for the Barcelona test given that the results obtained at a sectional level will reflect better the contribution of the fibres. On the other hand, this means that it is more likely to present instabilities in the precise moment that cracking occurs. It is important to remark, however, that the authors have not experienced any problem in the control of the test due to the higher dissipation of elastic energy in the moment of cracking.

\section{Analytical expressions for the tensile strength}

Several analytical expressions were reported in the literature for determining the direct tensile strength $\left(f_{c t}\right)$ derived from the DPT $[9,11,15-19]$. In Table 1, a summary of the closed-form expressions is presented. The main parameters are the maximum load $(P)$, the diameter and the height of the specimen ( $d$ and $h$, respectively) and the diameter of the plate $(d)$. These expressions allow determining the $f_{c t}$ for plain concrete and, in the case of the expression by Molins et al. [9], the residual strengths in the post-cracking stage. However, there is no formulation that provides the $\sigma-\varepsilon$ relation and that is valid for both the linear-elastic and post-cracking stages. 
Table 1. Analytical expressions for the tensile strength.

\begin{tabular}{lcc}
\hline \multicolumn{1}{c}{ Study } & Hypothesis / Approach & Expression \\
\hline Chen $(1970)^{1}$ & $\begin{array}{c}\text { Limit analysis of perfect elasto-plastic } \\
\text { material }\end{array}$ & $f_{c t}=\frac{P}{\pi\left(1.2 \frac{d}{2} h-\left(\frac{d^{\prime}}{2}\right)^{2}\right)}$ \\
Chen and Yuan (1980) & $\begin{array}{c}\text { Concrete as an elasto-plastic strain- } \\
\text { hardening and fracture material (FEM } \\
\text { analysis) }\end{array}$ & $f_{c t}=\frac{0.75 P}{\pi\left(1.2 \frac{d}{2} h-\left(\frac{d^{\prime}}{2}\right)^{2}\right)}$ \\
Bortolotti (1988) & $\begin{array}{c}\text { Modification of the Coulomb failure } \\
\text { criterion for concrete }\end{array}$ & $f_{c t}=\frac{P}{\pi\left(\frac{d}{2} h-\left(\frac{d^{\prime}}{2}\right)^{2} \cot \beta\right)}$ \\
Marti (1989) & $\begin{array}{c}\text { Non-linear fracture mechanics } \\
\text { Molins et al. (2007) }\end{array}$ & $f_{c t}=0.4 \frac{P}{4\left(\frac{d}{2}\right)^{2}} \sqrt{\left(1+\frac{d}{\lambda d_{a}}\right)}$ \\
\hline
\end{tabular}

1, 2: Both expressions are proposed in Chen and Yuan (1980).

3: where $\beta=\frac{\pi}{2}-\frac{\varphi}{2}$ is the failure angle and $\varphi$ is the internal friction angle.

4: where $d_{a}$ is the maximum aggregate size and $\lambda$ is an experimental parameter depending on the material.

\section{Formulation to predict the tensile behaviour of FRC}

\subsection{Formulation to estimate the stress $(\sigma)$}

All deductions are performed considering a cylindrical coordinate system with the longitudinal axis coinciding with the axis of the Barcelona test sample. Furthermore, only half of the sample is analysed in order to simplify de visualization of the phenomenon.

The cracking surface of the conical wedge is determined by the failure angle of the material $(\beta)$, which in turn depends of the interlocking effect between the aggregates and the fibres crossing the contact surface. After the cracking, the force applied by the metallic plate $\left(F_{P}\right)$ generates at the surface of the conical wedge a friction force $\left(F_{f r}\right)$ and a normal force $\left(F_{N}\right)$, as shown in Figure 2 a. To simplify the $2 \mathrm{D}$ representation, $F_{f r}$ and $F_{N}$ are positioned at one side even though in reality they are distributed all around surface. Figure $2 \mathrm{~b}$ shows the balance of forces acting. Notice that the force $F_{P}$ is completely balanced by the vertical components of $F_{f r}$ and $F_{N}$. However, a horizontal resulting radial force named $F_{R}$ appears. Such force is not out of balance since it is distributed all around the lateral surface pointing towards the centre of the conical wedge, thus cancelling itself.
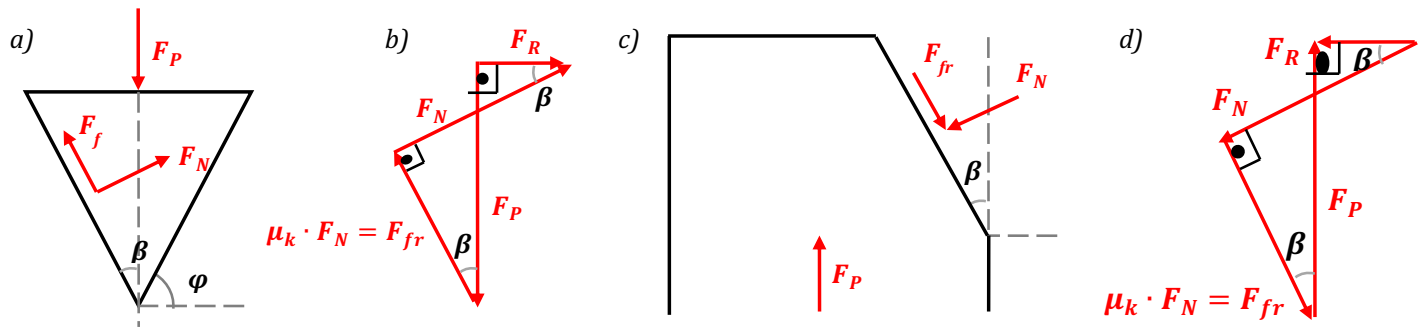

Figure 2. Detail of a) interplay of forces at the conical wedge, b) balance of forces at the conical wedge, c) interplay of forces at the specimen and d) balance of forces at the specimen.

The force $F_{f r}$ may be represented according with equation (Eq.1) as the product of a kinetic friction coefficient $\left(\mu_{k}\right)$ and the normal force $\left(F_{N}\right)$. It is important to remark that the kinetic friction coefficient should be used in this case since the conical wedge is constantly moving during the test. By applying equation (Eq.1) and simple trigonometry in Figure 3b, equations (Eq.2) and (Eq.3) may 
be deduced to estimate $F_{P}$ and $F_{R}$, respectively. After combining equations (Eq.2) and (Eq.3), equation (Eq.4) is obtained to estimate $F_{R}$ depending on the value of $F_{P}$.

$$
\begin{gathered}
F_{f r}=\mu_{k} \cdot F_{N} \\
F_{P}=F_{N} \cdot \operatorname{sen} \beta+F_{f r} \cdot \cos \beta=F_{N} \cdot\left(\operatorname{sen} \beta+\mu_{k} \cdot \cos \beta\right) \\
F_{R}=F_{N} \cdot \cos \beta+F_{f r} \cdot \operatorname{sen} \beta=F_{N} \cdot\left(\cos \beta-\mu_{k} \cdot \operatorname{sen} \beta\right) \\
F_{R}=F_{P} \cdot \frac{\cos \beta-\mu_{k} \cdot \operatorname{sen} \beta}{\operatorname{sen} \beta+\mu_{k} \cdot \cos \beta}
\end{gathered}
$$

By the principle of action and reaction, the forces applied to the conical wedge should also be applied with the same magnitude and opposite direction to the rest of the specimen. This is represented in Figure 2c along with the balance of forces (see Figure 2d). Again, a resulting radial force appears with a magnitude that could be estimated through equation (Eq.4). However, due to the presence of radial cracks, in this case $F_{R}$ must be generated by the contribution of the fibres.

This contribution is estimated using the infinitesimal slice from Figure 3. This slice receives a normal stress that balances the infinitesimal radial force $d F_{r}$. In order to simplify the deduction it is assumed that an average normal stress $(\sigma)$ is uniformly distributed over the whole area of the cracked radial surface $(A)$. Before the main cracks appear, the concrete behaves as a monolithic element and the resistant mechanism generates a non-uniform stress distribution. Once the cracks are formed, the stress produced inside the specimen is governed in the cracked sections by the pullout response of the fibres [20].

a)



b)

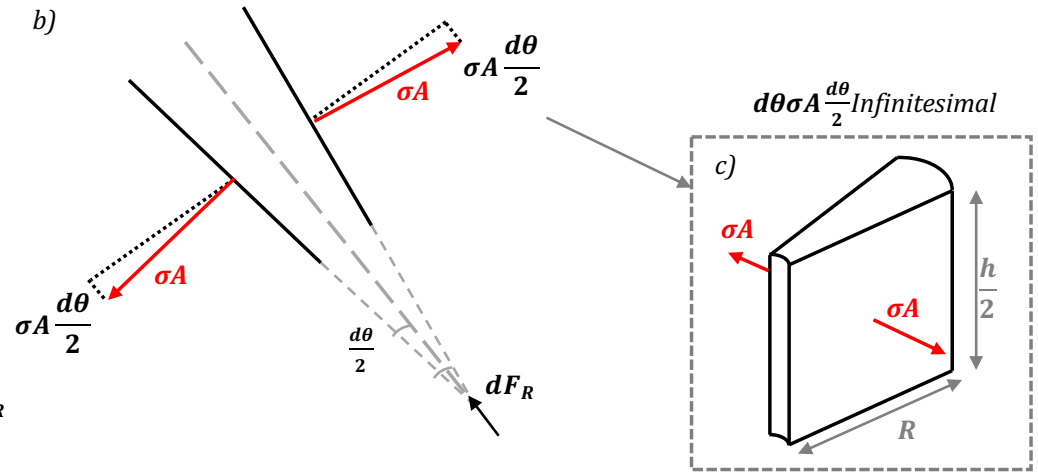

Figure 3. Infinitesimal slice of a concrete segment.

It is observed that during the test an approximately constant opening appears throughout the cracking plane. In other words, the crack width close to the centre of the specimen is approximately the same as at the perimeter. Consequently, the stress distribution generated by the pull-out of fibres may be assumed as uniformly distributed in the cracking surface. It is important to remark that, in reality, a slight differential opening might exist. However, the consideration of a uniform stress is a fare estimate that is on the safe side.

Considering the previous assumption, the resulting force acting at the cracks must equal $\sigma \cdot A$ (see Figure 3c). In this context, the equilibrium of forces in the infinitesimal slice may be represented through equation (Eq.5), which considers that for small values $\sin d \theta \approx d \theta$. The total value of $F_{R}$ in cylindrical coordinates may be obtained by integrating equation (Eq.5) around the complete circumferential angular section, leading to equation (Eq.6). 


$$
\begin{gathered}
d F_{R}=2 \cdot \sigma \cdot A \cdot \frac{d \theta}{2}=\sigma \cdot A \cdot d \theta \\
F_{R}=\int_{0}^{2 \pi} d F_{R}=2 \cdot \pi \cdot \sigma \cdot A
\end{gathered}
$$

Substituting equation (Eq.4) in (Eq.5) gives equation (Eq.7), which allows the estimation of the tensile stress $(\sigma)$ resisted by the FRC depending of the load applied by the press $\left(F_{P}\right)$. In this case, the area of the cracked radial surface $(A)$ should be obtained in equation (Eq.8) as the area of the sectional cut of one quarter of the specimen subtracted by the sectional area of half of one conical wedge, which is not part of the cracked surface.

$$
\begin{gathered}
\sigma=\frac{F_{P}}{2 \cdot \pi \cdot A} \cdot \frac{\cos \beta-\mu_{k} \cdot \operatorname{sen} \beta}{\operatorname{sen} \beta+\mu_{k} \cdot \cos \beta} \\
A=\frac{d \cdot h}{4}-\frac{d^{\prime 2}}{4 \cdot \tan \beta}
\end{gathered}
$$

\subsection{Formulation to estimate the strain $(\varepsilon)$}

During the test, the specimen is divided in a number of segments that equals the total number $n$ of cracks formed. In order to simplify the deduction it is assumed that all concrete segments have the same size with an internal angle $2 \pi / n$. When the kinematic mechanism starts, each conical wedge slide $d \delta_{P} / 2$ into the specimen leading to the lateral displacement of the concrete segments $\left(d \delta_{L}\right)$, which is depicted in Figure 4a.

a)

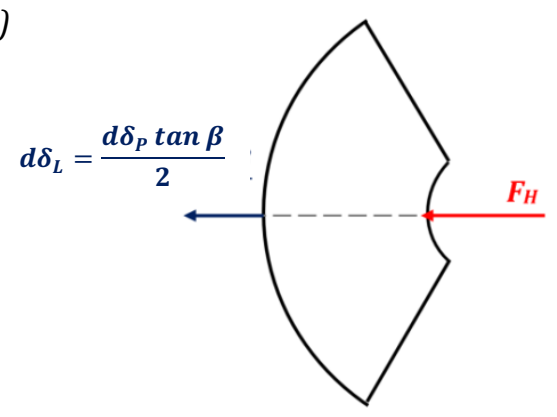

b)

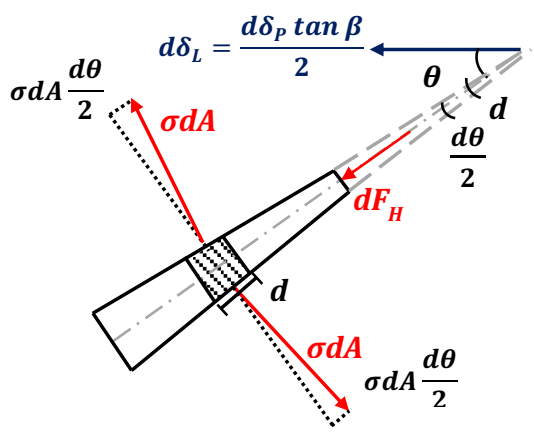

Figure 4. a) Lateral displacement of concrete segment and b) infinitesimal section of segment.

Both displacements are related with the angle $\beta$ of the conical wedge according to equation (Eq.9). Consider an infinitesimal element in a slice of the concrete segment (see Figure $4 \mathrm{~b}$ ) with a lateral area $d A$ that equals $d R \cdot d h$. The differential work $(d \tau)$ done by the tensile stress in this element may be expressed as shown in equation (Eq.10). Notice that the lateral displacement occurs with the same direction and magnitude in all infinitesimal elements since it may be assumed that the concrete segments move as independent bodies.

$$
\begin{gathered}
d \delta_{L}=\frac{d \delta_{P}}{2} \cdot \tan \beta \\
d \tau=\left(2 \sigma d A \frac{d \theta}{2}\right) \cdot d \delta_{L} \cdot \cos \theta=\sigma \cdot d h \cdot d R\left(\frac{d \delta_{P}}{2} \tan \beta\right) \cdot \cos \theta \cdot d \theta
\end{gathered}
$$

In this context, the work produced at each segment may be calculated through the sum of $d \tau$ for all infinitesimal elements included in the segment. This is equivalent to a triple integration of $d \tau$ in the interval $(-\pi / n, \pi / n)$, for a radius ranging from 0 to the radius of the specimen $(R)$ and for a height 
varying from 0 to half the height of the specimen $(h / 2)$, as shown in equation (Eq.11). The latter may be multiplied by the number of segments $(n)$ to obtain the total work of the specimen, which is shown in equation (Eq.12).

$$
\begin{gathered}
\tau_{n}=\int_{0}^{\frac{h}{2}} \int_{0}^{R} \int_{\frac{-\pi}{n}}^{\frac{\pi}{n}} d \tau=\sigma \cdot \frac{h}{2} \cdot R \cdot d \delta_{P} \cdot \tan \beta \cdot \sin \left(\frac{\pi}{n}\right) \\
\tau=n \cdot \tau_{n}=n \cdot \sigma \cdot \frac{h}{2} \cdot R \cdot d \delta_{P} \cdot \tan \beta \cdot \sin \left(\frac{\pi}{n}\right)
\end{gathered}
$$

Suppose now an equivalent specimen subjected to the same kinematic mechanism but that was not allowed to have radial cracks. In this case, the lateral displacement $\delta_{L}$ experienced would be caused by a circumferential deformation due to the tensile stresses (Figure 5).
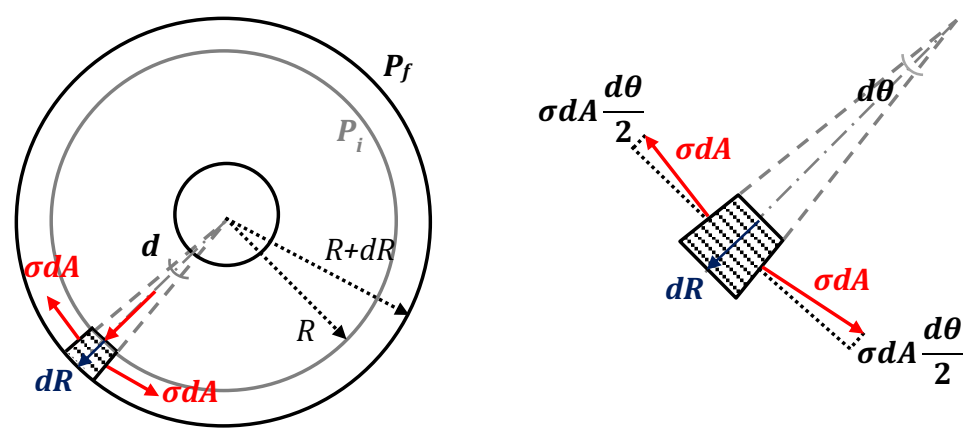

Figure 5. Circumferential deformation of the specimen.

The circumferential deformation may be written according with equation (Eq.13). The latter is the used in equation (Eq.14) to estimate the work done by the tensile stress in an infinitesimal element with a lateral area $d A$.

$$
\begin{gathered}
\varepsilon=d R / R \\
d \tau=2 \cdot \sigma \cdot d A \cdot \frac{d \theta}{2} \cdot d R=\sigma \cdot d h \cdot d R \cdot d \theta \cdot(R \cdot \varepsilon)
\end{gathered}
$$

Following the same procedure described previously, the total work of the specimen is estimated through the triple integration of $d \tau$ in the interval $(-\pi, \pi)$, for a radius ranging from 0 to the radius of the specimen $(R)$ and for a height varying from 0 to half the height of the specimen $(h / 2)$, as shown in equation (Eq.15).

$$
\tau=\int_{0}^{\frac{h}{2}} \int_{0}^{R} \int_{-\pi}^{\pi} d \tau=\frac{2 \pi \cdot \sigma \cdot h \cdot \varepsilon \cdot R^{2}}{4}=\pi \cdot \sigma \cdot \frac{h}{2} \cdot \varepsilon \cdot R^{2}
$$

Assuming that the circumferential deformation of the specimen is equivalent to the lateral displacement of the concrete section, the increments of work in (Eq.11) and (Eq.12) may be considered equal, as shown in expression (Eq.16) and in (Eq.17).

$$
\begin{gathered}
n \cdot \sigma \cdot \frac{h}{2} \cdot R \cdot d \delta_{P} \cdot \tan \cdot \beta \cdot \sin \left(\frac{\pi}{n}\right)=\pi \cdot \sigma \frac{h}{2} \cdot \varepsilon \cdot R^{2} \\
n \cdot d \delta_{P} \cdot \tan \beta \cdot \sin \left(\frac{\pi}{n}\right)=\pi \cdot \varepsilon \cdot R
\end{gathered}
$$

Finally, the strain in the specimen may be written as in expression (Eq.18) or in terms of increments as in equation (Eq.19). 


$$
\begin{aligned}
\varepsilon & =\frac{n \delta_{P}}{\pi R} \cdot \tan \beta \cdot \sin \left(\frac{\pi}{n}\right) \\
\Delta \varepsilon & =\frac{n \Delta \delta_{P}}{\pi R} \cdot \tan \beta \cdot \sin \left(\frac{\pi}{n}\right)
\end{aligned}
$$

\subsection{Values of failure angle ( $\beta)$, friction coefficient $(\mu)$ and number of cracks ( $n)$}

In the formulation proposed, the values of the failure angle $(\beta)$, the kinetic friction coefficient $\left(\mu_{k}\right)$ and the number of cracks $(n)$ are required. The value of $\beta$ is usually defined in the literature by means of the internal friction angle of the material $(\varphi)$ since it determines the cracking surface of the conical wedge. A review on the different values for $\varphi$ proposed by several authors during the past 50 years may be found in [12]. The actual length of the conical wedge was measured in the experiences conducted at the Laboratory of Structure Technology Luis Agulló. Figure 6a shows the procedure of opening the specimen, which was performed avoiding any damage of the conical wedge.
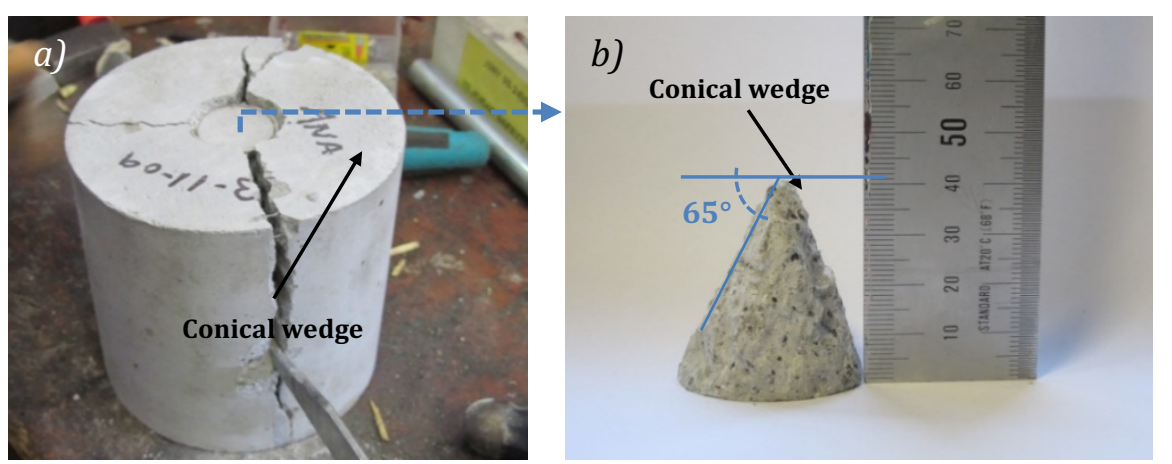

Figure 6. a) Opening of the specimen and b) measurements of the length of the conical wedge.

After the conical wedge was separated from the concrete segments, its length was measured as observed in Figure 6b. The measurements revealed that the length of the conical wedge $(I)$ is approximately $40 \mathrm{~mm}$. Taking into account the dimensions of the steel punch $\left(d^{\prime}=37.5 \mathrm{~mm}\right)$ and using expression (Eq.20), the internal friction angle is $65^{\circ}$. Hence, the values are $\varphi=65^{\circ}$ and $\beta=25^{\circ}$.

$$
l=\frac{d^{\prime}}{2} \cdot \tan \varphi
$$

Regarding the friction coefficient, the values presented in the literature usually cover the static friction coefficient of concrete $\left(\mu_{s}\right)$. Nevertheless, very limited information is available for the kinetic friction coefficient $\left(\mu_{k}\right)$. It is known that the value of $\mu_{k}$ for the same surface tends to be smaller than $\mu_{s}$. This should be especially true for two cracked concrete surfaces subjected to considerable relative displacement, such as observed in the Barcelona test. As the surfaces start moving, the roughness is smoothened due to the cracking of their irregularities, thus reducing the values of the friction coefficient. In Figure $6 \mathrm{~b}$ a detail of the surface of the conical wedge after the test is presented.

In the absence of reliable values of $\mu_{k}$, the $\mu_{s}$ proposed in the Model Code 2010 [21] and summarized in Table 2 is used as a reference. Considering the aspect of the conical wedge after the test, it is assumed that the $\mu_{s}$ should be in the range of rough surfaces. However, the value should be reduced to take into account the differences between $\mu_{k}$ and $\mu_{s}$ as well as the mechanism observed during the test. Then, a $\mu_{k}$ equal to 0.7 is considered a reasonable initial approximation. It is 
important to remark that more studies are required to characterize $\mu_{k}$ and the variables affecting this parameter.

Table 2. Friction coefficient for plain concrete according to the Model Code 2010.

\begin{tabular}{cc}
\hline Interface roughness & Friction coefficient $\boldsymbol{\mu}[-]$ \\
\hline Smooth interface & $0.5-0.7$ \\
Rough interface & $0.7-1.0$
\end{tabular}

The number of cracks $(n) \quad$ Very rough interface $1.0-1.4 \quad$ may be determined experimentally through the observation of the specimens after the test. The influence of this parameter on the final stress-strain curve with the constitutive model proposed here is presented in Figure 7. For that, the experimental result of the characterisation of one specimen was used considering $n$ values of 2, 3 and 4 . It is evident that, the change in $n$ does not affect significantly the shape nor the absolute values of stress estimated for a certain strain. Therefore, if no information on the number of cracks is available, a number of cracks equal to 3 may be adopted since it is the most common outcome.

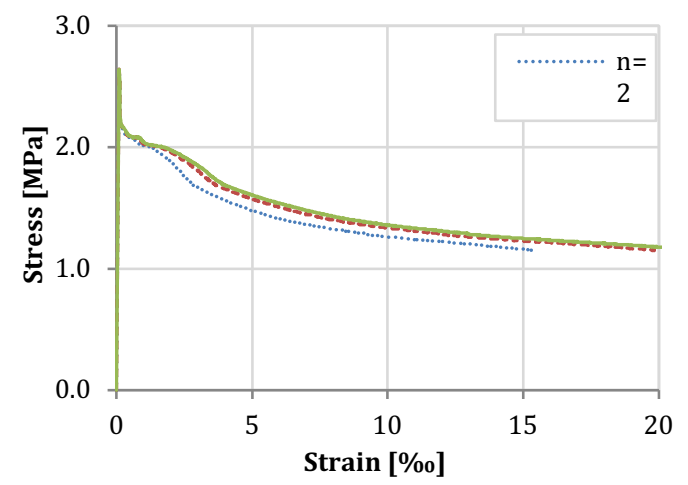

Figure 7. Influence of the number of cracks (n) on the constitutive model.

\section{Experimental program}

In order to validate the formulation proposed and to compare the new formulation with the constitutive models from European codes and guidelines based on flexural tests, the results of three experimental studies involving Barcelona tests and 3-point bending tests are considered. These results correspond to four series of SFRC, two of them from [23] and the other two from [24]. Two series of PFRC from the study of [6] were also analysed. In Table 3, the specimens of the Barcelona test (C) and the beams bending test (B) are listed according to their corresponding reference. These were produced according to [10] and [22], respectively.

Table 3. Series of FRC beams and cylinders.

\begin{tabular}{ccccc}
\hline Series & Reference & Cylinders (C) & Beams (B) & Notation \\
\hline A40 & Blanco 2013 & 5 & 6 & A40_C1 or A40_B2 \\
A60 & Blanco 2013 & 2 & 1 & A60_C2 or A60_B3 \\
B30 & Monsó 2011 & 10 & 8 & B30_C3 or B30_B4 \\
B50 & Monsó 2011 & 10 & 10 & B50_C4 or B50_B5 \\
C5 & Pujadas 2014 & 6 & 3 & C5_C5 or C5_B6 \\
C7 & Pujadas 2014 & 5 & 3 & C7_C6 or C7_B1 \\
\hline
\end{tabular}

According to the notation adopted, the letters A, B and C identify a different type of fibre and the number following the letter corresponds to the fibre content (in $\mathrm{kg} / \mathrm{m}^{3}$ ). The letters $\mathrm{B}$ and $\mathrm{C}$, appended at the end, differentiate the cylindrical specimens from the beams, followed by a number 
identifying the specimens of the series. The type of fibre used steel fibre (SF) or plastic fibre (PF) and additional fibre characteristics are presented in Table 4.

Table 4. Characteristics of the fibres (provided by the manufacturer).

\begin{tabular}{lcccc}
\hline \multicolumn{1}{c}{ Characteristics } & Unit & A & B & C \\
\hline Material & - & SF & SF & PF \\
Length $(L)$ & {$[\mathrm{mm}]$} & 50 & 50 & 48 \\
Diameter $(d)$ & {$[\mathrm{mm}]$} & 0.62 & 1.05 & - \\
Aspect ratio $(L / d)$ & {$[-]$} & 83 & 48 & - \\
Tensile strength $\left(f_{y}\right)$ & {$[\mathrm{MPa}]$} & 1270 & 1115 & 550 \\
Modulus of elasticity $(E)$ & {$[\mathrm{GPa}]$} & 210 & 210 & 10 \\
Number of fibres per kg & {$[-]$} & 8100 & 2800 & 35000 \\
\hline
\end{tabular}

The average results at 28 days of the compressive strength $\left(f_{\mathrm{cm}}\right)$ and the modulus of elasticity $\left(E_{\mathrm{cm}}\right)$ assessed according to UNE 83507:2004 [25] and UNE 83316:1996 [26], respectively, are presented in Table 5. The results of the flexural test included in Table 6 correspond to the average values of the limit of proportionality $\left(f_{L}\right)$ and the residual flexural tensile strengths $f_{R 1}, f_{R 2}, f_{R 3}$ and $f_{R 4}$ associated to crack mouth opening CMOD of $0.05 \mathrm{~mm}, 0.50 \mathrm{~mm}, 1.50 \mathrm{~mm}, 2.50 \mathrm{~mm}$ and $3.50 \mathrm{~mm}$, respectively, according to EN14651:2005 [22].

Table 5. Main properties of the FRC series.

\begin{tabular}{|c|c|c|c|c|c|c|c|c|}
\hline \multicolumn{3}{|c|}{ Characteristics } & A40 & A60 & B30 & B50 & C5 & C7 \\
\hline \multirow{2}{*}{ Modulus of elasticity } & \multirow{2}{*}{$E_{c m}$} & Avg. $[\mathrm{MPa}]$ & 29029 & 31597 & 30200 & 30000 & 31150 & 31930 \\
\hline & & $C V[\%]$ & 0.96 & 1.10 & - & - & 1.69 & 2.14 \\
\hline \multirow{2}{*}{ Compressive strength } & \multirow{2}{*}{$f_{c m}$} & Avg. [MPa] & 46.73 & 54.30 & 44.85 & 43.97 & 52.15 & 54.64 \\
\hline & & CV [\%] & 0.77 & 1.51 & 1.80 & 4.80 & 1.52 & 0.82 \\
\hline \multirow{10}{*}{ Residual flexural strengths } & \multirow{2}{*}{$f_{L}$} & Avg. [MPa] & 5.29 & 3.72 & 13.14 & 13.76 & 4.61 & 5.14 \\
\hline & & $C V[\%]$ & 2.23 & - & 9.4 & 7.5 & 2.19 & 8.71 \\
\hline & \multirow{2}{*}{$f_{R 1}$} & Avg. [MPa] & 6.13 & 6.40 & 3.73 & 8.58 & 2.01 & 3.59 \\
\hline & & CV [\%] & 13.71 & - & 40.3 & 21.9 & 22.30 & 9.20 \\
\hline & \multirow{2}{*}{$f_{R 2}$} & Avg. [MPa] & 7.04 & 6.12 & 3.91 & 9.47 & 2.25 & 4.66 \\
\hline & & $C V[\%]$ & 15.77 & - & 45.3 & 28.5 & 28.53 & 7.05 \\
\hline & \multirow{2}{*}{$f_{R 3}$} & Avg. [MPa] & 7.08 & 6.24 & 3.89 & 9.29 & 2.46 & 5.14 \\
\hline & & $C V[\%]$ & 15.05 & - & 50.0 & 32.0 & 26.84 & 6.50 \\
\hline & \multirow{2}{*}{$f_{R 4}$} & Avg. [MPa] & 6.62 & 6.47 & 3.62 & 8.88 & 2.48 & 5.17 \\
\hline & & $\mathrm{CV}[\%]$ & 12.08 & - & 48.7 & 32.3 & 23.47 & 6.43 \\
\hline
\end{tabular}

It should be remarked that the study by [24] does not provide any results regarding $E_{c m}$ and the values were estimated from $f_{c m}$ with the formulation in the Spanish code EHE-08 [27]. Notice that due to the control device malfunctioning; only the results of one beam are available for A60.

\section{Simplified model}

Following the approach of the current European design codes and guidelines for FRC, which include simplified constitutive models, a simplified version of the formulation is proposed in the shape of a multilinear $\sigma-\varepsilon$ diagram, as indicated in Figure 8. Table 6 summarizes the parameters defining the simplified $\sigma-\varepsilon$ diagram derived from the Barcelona test. Notice that the values stresses may be expressed as function of the load associated to a certain displacement, considering the constant $(\omega)$. The procedure followed to obtain the simplified version is described in Appendix A. 
Table 6. Parameters of the simplified model.

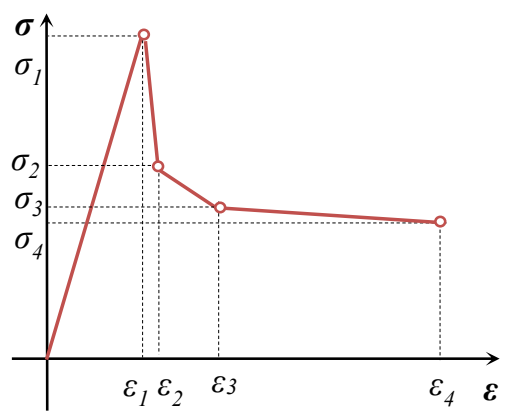

\begin{tabular}{cc}
\hline Strain [\%o] & Stress [MPa] \\
\hline$\varepsilon_{1}=\frac{\sigma_{1}}{E_{c m}}$ & $\sigma_{1}=\frac{F_{P \max }}{2 \cdot \pi \cdot A} \cdot \frac{\cos \beta-\mu_{k} \cdot \operatorname{sen} \beta}{\operatorname{sen} \beta+\mu_{k} \cdot \cos \beta}=\omega F_{P \max }$ \\
$\varepsilon_{2}=\varepsilon_{1}+0.1$ & $\sigma_{2}=\frac{F_{P 0.02 \mathrm{~mm}}}{2 \cdot \pi \cdot A} \cdot \frac{\cos \beta-\mu_{k} \cdot \operatorname{sen} \beta}{\operatorname{sen} \beta+\mu_{k} \cdot \cos \beta}=\omega F_{P 0.02 \mathrm{~mm}}$ \\
$\varepsilon_{3}=4.0$ & $\sigma_{3}=\frac{F_{P 0.75 \mathrm{~mm}}}{2 \cdot \pi \cdot A} \cdot \frac{\cos \beta-\mu_{k} \cdot \operatorname{sen} \beta}{\operatorname{sen} \beta+\mu_{k} \cdot \cos \beta}=\omega F_{P 0.75 \mathrm{~mm}}$ \\
$\varepsilon_{4}=20$ & $\sigma_{4}=\frac{F_{P 4.00 \mathrm{~mm}}}{2 \cdot \pi \cdot A} \cdot \frac{\cos \beta-\mu_{k} \cdot \operatorname{sen} \beta}{\operatorname{sen} \beta+\mu_{k} \cdot \cos \beta}=\omega F_{P 4.00 \mathrm{~mm}}$ \\
\hline
\end{tabular}

Figure 8. Simplified $\sigma-\varepsilon$ diagram.

Figure 9 shows the comparison between the simplified and the complete $\sigma$ - $\varepsilon$ models deducted in this study for one specimen of series A40, A60, B30, B50, C5 and C7. The curves reveal a good fit and the validity for steel and plastic fibres as well as for different fibre contents of the simplified model, which represents with good accuracy the shape of the curve.
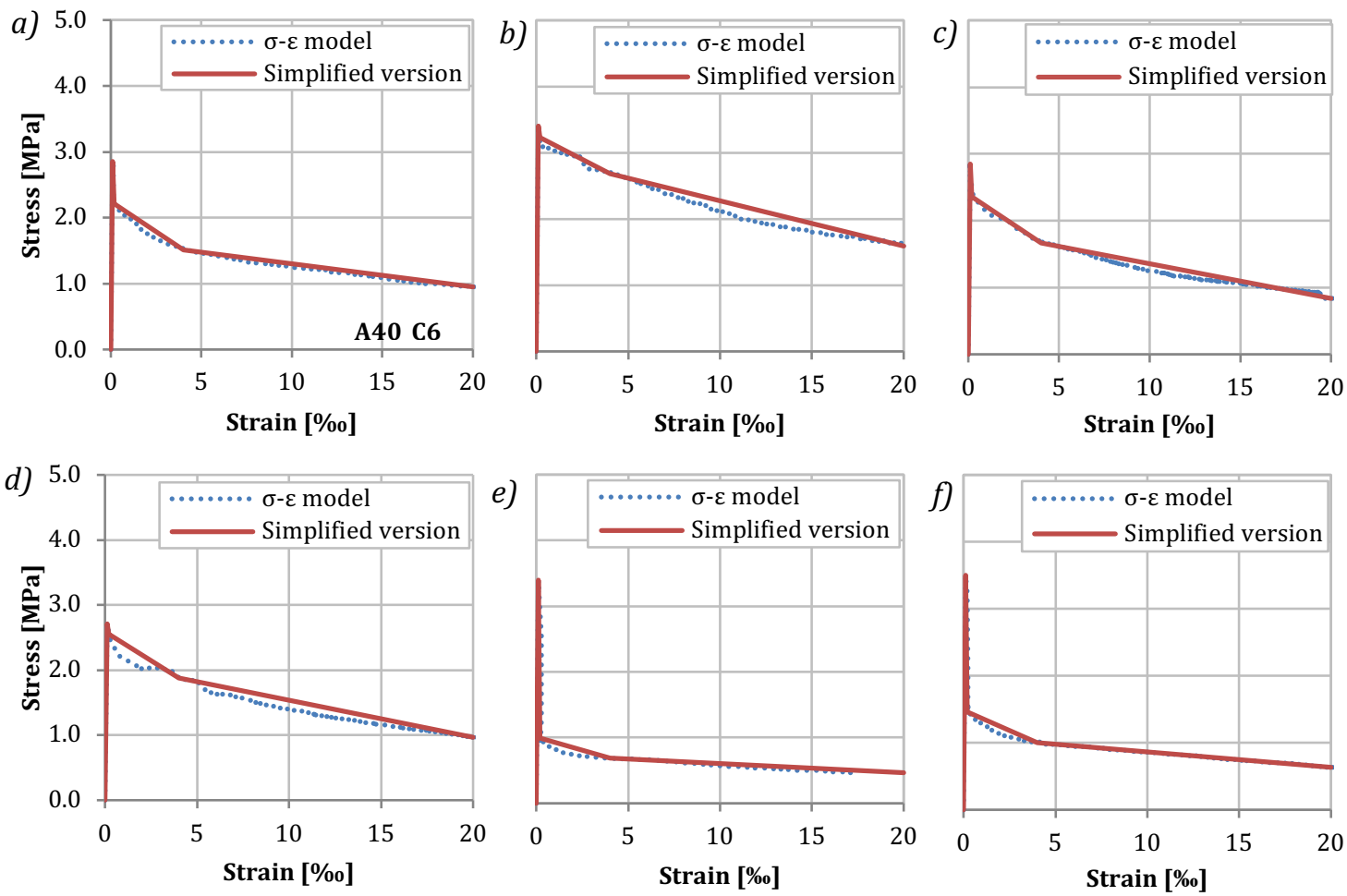

Figure 9. Complete and simplified models for a) A40_C6, b) A60_C2, c) B30_C5, d) B50_C2, e) C5_C1 and f) C7_C2.

\section{Numerical validation}

\subsection{Model type and geometry}

The finite element software DIANA 9.4 was chosen to model the Barcelona test due to its extensive material library and analysis capabilities. The setup of the test required a 3D analysis, using solid and interface elements to simulate the behaviour of the specimen during the test. Given the symmetry of the test, only half of the specimen was modelled to favour the efficiency of the analysis and a more refined mesh discretization (see Figures 10a, 10b and 10c). Furthermore, the steel punch used in the Barcelona test to transmit the load to the specimen was not modelled. Instead, the load was directly applied in an equivalent area on the top surface of the FRC specimen. 


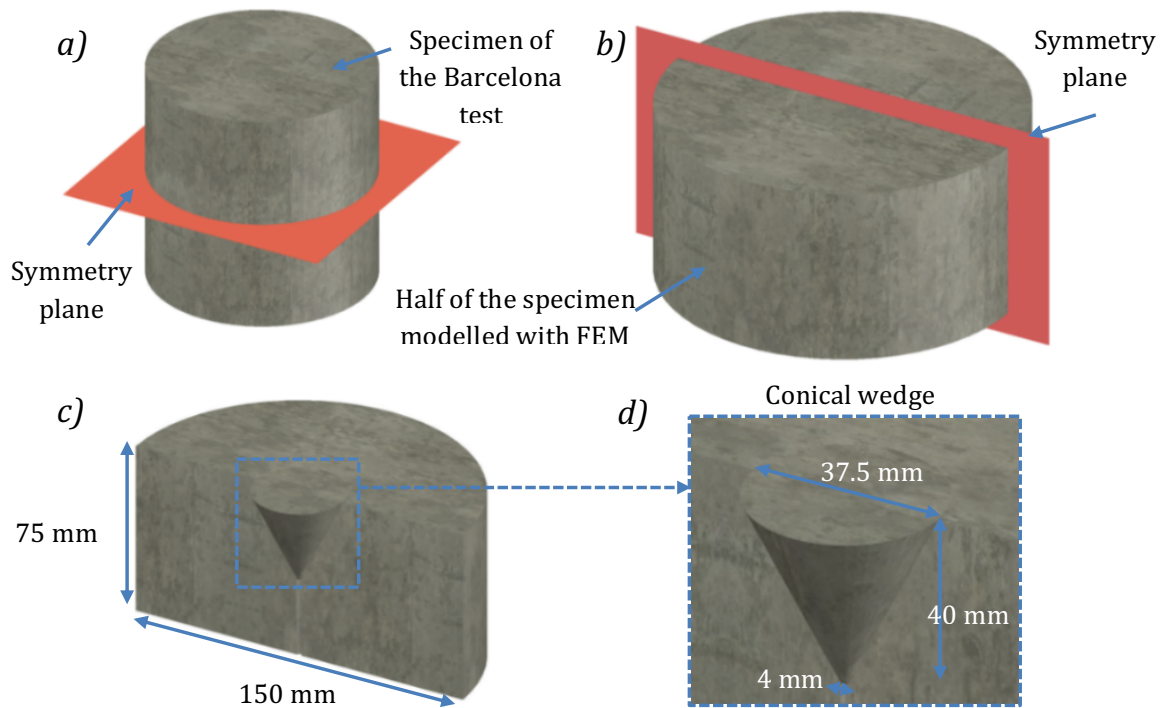

Figure 10. a) Specimen of the Barcelona test, b) half of the specimen modelled with FEM, c) definition of the conical wedge in the model and d) detail of the conical wedge.

The fracture process leads to a change of the resistant mechanism. This change is difficult to reproduce with a single mesh for all the volume since it entails localized large displacements at certain locations (particularly in the formation of the cone) that may cause divergences and a different response from the real one. For this reason, the specimen was not addressed as a single volume but as the summation of the cone and the rest of the specimen. This approach of predefining the failure mechanism in a double punch test was already applied in previous studies by defining the failure planes [28]. In addition, to avoid concentrated loads in the vertex, the cone was approximated as an inverted truncated cone with a top diameter equal to that of the steel punch, a bottom diameter of $4 \mathrm{~mm}$ and a height of $40 \mathrm{~mm}$ (see Figure 10d).

An interface element was defined between the lateral surface of the cone and the specimen to allow the displacement of the cone and the cracking. The meshes of each of the 4 parts of the specimen were radially generated so as to reduce the influence that the discretization adopted may have on the mesh and the results. Symmetry conditions were imposed by restraining the vertical displacement of the bottom face of the half specimen. The load case consisted of a vertical displacement acting simultaneously at all nodes on the loading surface. Each load step was equivalent to a vertical displacement of $0.025 \mathrm{~mm}$.

\subsection{Material properties}

A fracture energy based on total strain rotating crack model [29] was used for the FRC of the specimens assuming the multilinear $(\sigma-\varepsilon)$ curve in tension proposed in section 5. General characteristics and the parameters of this model were established in accordance with Eurocode 2 [30]. Since no cracking is expected in the cone (as observed experimentally), for efficiency purposes it was defined as an elastic material with a modulus of elasticity equal to that of the corresponding FRC. The interface material between the cone and the rest of the specimen is characterized by a linear normal and linear tangential stiffness and a frictional behaviour simulated using a Coulomb friction model with a brittle gapping criterion.

Table 7 includes a summary of the main properties of the materials. Notice that for the validation of the formulation six types of FRC were considered: four of SFRC (A40, A60, B30 and B50) and two of PFRC (C5 and C7). Notice that the same base mixture composition was used for A40 and A60, changing only the fibre content from $40 \mathrm{~kg} / \mathrm{m}^{3}$ in the former to $60 \mathrm{~kg} / \mathrm{m}^{3}$ in the latter. The same 
holds true for the mixture B30 and B50 with fibre contents respectively of $30 \mathrm{~kg} / \mathrm{m}^{3}$ and $60 \mathrm{~kg} / \mathrm{m}^{3}$ and for $\mathrm{C} 5$ and $\mathrm{C} 7$, which present $5 \mathrm{~kg} / \mathrm{m}^{3}$ and $7 \mathrm{~kg} / \mathrm{m}^{3}$. To simplify the presentation of the information, the main properties of the FRC are classified according to series A (for A40 and A60), B (for B30 and B50) and C (for C5 and C7). Only two specimens per each series and fibre content are presented since the tendencies are similar.

Table 7. Material properties considered in the FEM model.

\begin{tabular}{|c|c|c|c|}
\hline Model part & Material properties & Value & Reference \\
\hline \multirow{4}{*}{ Interface material } & Normal stiffness $\left[\mathrm{MN} / \mathrm{m}^{3}\right]$ & $1.0 \cdot 10^{5}$ & \\
\hline & Tangential stiffness $\left[\mathrm{MN} / \mathrm{m}^{3}\right]$ & $1.0 \cdot 10^{5}$ & \\
\hline & Tangent of friction angle & 0.7 & \\
\hline & Tangent of dilatancy angle & 0.0 & \\
\hline \multirow{2}{*}{ Conical wedge } & Poisson ratio [-] & 0.2 & Eurocode 2 \\
\hline & Average modulus of elasticity [GPa] & 2.9 / 3.2/ 3.0/3.0/ 3.1/ 3.2 & $\mathrm{~A} 40 / \mathrm{A} 60 / \mathrm{B} 30 / \mathrm{B} 50 / \mathrm{C} 5$ /C7 \\
\hline \multirow{11}{*}{$\begin{array}{c}\text { SFRC } \\
\text { (Series A) }\end{array}$} & Average compressive strength[MPa] & $46.7 / 54.3$ & $\mathrm{~A} 40 / \mathrm{A} 60$ \\
\hline & Average modulus of elasticity [GPa] & $29.0 / 31.6$ & $\mathrm{~A} 40 / \mathrm{A} 60$ \\
\hline & Poisson ratio [-] & 0.2 & Eurocode 2 \\
\hline & Tensile strength $\sigma_{1}[\mathrm{MPa}]$ & 2.9 / 2.9 / $3.3 / 3.4$ & $\mathrm{~A} 40 \_\mathrm{C} 5$ /_C6 / A60_C1 /_C2 \\
\hline & Residual strength $\sigma_{2}[\mathrm{MPa}]$ & $2.4 / 2.2$ / $3.2 / 3.2$ & $\mathrm{~A} 40 \_\mathrm{C} 5$ / _C6 / A60_C1 /_C2 \\
\hline & Residual strength $\sigma_{3}[\mathrm{MPa}]$ & $2.0 / 1.5 / 2.7 / 2.8$ & A40_C5 /_C6 / A60_C1 /_C2 \\
\hline & Residual strength $\sigma_{4}[\mathrm{MPa}]$ & $1.3 / 1.0 / 1.6 / 1.7$ & A40_C5 /_C6 / A60_C1 /_C2 \\
\hline & Strain $\varepsilon_{1}[\% 0]$ & 0.1 & A40_C5 /_C6 / A60_C1 /_C2 \\
\hline & Strain $\varepsilon_{2}[\% 0]$ & 0.2 & $\mathrm{~A} 40 \_\mathrm{C} 5$ /_C6 / A60_C1 /_C2 \\
\hline & Strain $\varepsilon_{3}[\% 0]$ & 4.0 & A40_C5 /_C6 / A60_C1 /_C2 \\
\hline & Strain $\varepsilon_{4}[\% 0]$ & 20.0 & A40_C5 /_C6 / A60_C1 /_C2 \\
\hline \multirow{11}{*}{$\begin{array}{c}\text { SFRC } \\
\text { (Series B) }\end{array}$} & Average compressive strength[MPa] & $44.9 / 44.0$ & B30 / B50 \\
\hline & Average modulus of elasticity [GPa] & $30.2 / 30.0$ & $\mathrm{~B} 30$ / B50 \\
\hline & Poisson ratio [-] & 0.2 & Eurocode 2 \\
\hline & Tensile strength $\sigma_{1}[\mathrm{MPa}]$ & $2.8 / 2.5 / 2.7 / 2.8$ & B30_C5 /_C8 / B50_C2 /_C8 \\
\hline & Residual strength $\sigma_{2}[\mathrm{MPa}]$ & $2.4 / 2.0 / 2.5 / 2.3$ & B30_C5 /_C8 / B50_C2 /_C8 \\
\hline & Residual strength $\sigma_{3}[\mathrm{MPa}]$ & $1.6 / 1.6 / 1.9 / 1.4$ & $\mathrm{~B} 30 \_\mathrm{C} 5$ /_C8 / B50_C2 /_C8 \\
\hline & Residual strength $\sigma_{4}[\mathrm{MPa}]$ & $0.7 / 0.9 / 1.0 / 0.9$ & B30_C5 /_C8 / B50_C2 /_C8 \\
\hline & Strain $\varepsilon_{1}[\% 0]$ & 0.1 & B30_C5 /_C8 / B50_C2 /_C8 \\
\hline & Strain $\varepsilon_{2}[\% 0]$ & 0.2 & B30_C5 /_C8 / B50_C2 /_C8 \\
\hline & Strain $\varepsilon_{3}[\% 0]$ & 4.0 & B30_C5 /_C8 / B50_C2 /_C8 \\
\hline & Strain $\varepsilon_{4}[\% 0]$ & 20.0 & B30_C5 /_C8 / B50_C2 /_C8 \\
\hline \multirow{11}{*}{ PFRC } & Average compressive strength[MPa] & $52.2 / 54.6$ & $\mathrm{C} 5 / \mathrm{C} 7$ \\
\hline & Average modulus of elasticity [GPa] & $31.3 / 32.1$ & $\mathrm{C} 5 / \mathrm{C} 7$ \\
\hline & Poisson ratio [-] & 0.2 & Eurocode 2 \\
\hline & Tensile strength $\sigma_{1}[\mathrm{MPa}]$ & $3.3 / 3.1 / 3.5 / 3.3$ & C5_C2 / _C5 / C7_C2 /_C5 \\
\hline & Residual strength $\sigma_{2}[\mathrm{MPa}]$ & $1.4 / 1.8 / 1.5 / 1.8$ & C5_C2 /_C5 / C7_C2 /_C5 \\
\hline & Residual strength $\sigma_{3}[\mathrm{MPa}]$ & $0.8 / 1.0 / 1.0 / 0.9$ & C5_C2 /_C5 / C7_C2 /_C5 \\
\hline & Residual strength $\sigma_{4}[\mathrm{MPa}]$ & $0.5 / 0.6 / 0.6 / 0.6$ & C5_C2 /_C5 / C7_C2 /_C5 \\
\hline & Strain $\varepsilon_{1}[\% 0]$ & 0.1 & C5_C2 /_C5 / C7_C2 /_C5 \\
\hline & Strain $\varepsilon_{2}[\% 0]$ & 0.2 & $\mathrm{C} 5 \_\mathrm{C} 2$ /_C5 / C7_C2 /_C5 \\
\hline & Strain $\varepsilon_{3}[\% 0]$ & 4.0 & C5_C2 /_C5 / C7_C2 /_C5 \\
\hline & Strain $\varepsilon_{4}[\% 0]$ & 20.0 & C5_C2 /_C5 / C7_C2 /_C5 \\
\hline
\end{tabular}

Taking into account the inspections of the specimens after the Barcelona test and the considerations included in section 4.3, a failure angle $(\beta)$ of 0.438 rad and a dynamic friction angle $\left(\mu_{k}\right)$ of 0.7 were used in all FEM and in the simplified model proposed here. It was also assumed that the number of cracks $(n)$ that appear during the test was 3 since this is the most common outcome of the test. 


\subsection{Results}

In Figure 11, the experimental and the predicted curves are compared for two specimens of each series. It must be remarked that in the experimental results there is an accommodation effect between the surfaces of the piston and the specimen (due to irregularities of the surface of the specimen) that leads to larger displacements in the early stages. This effect was not observed in the simulation with the finite element software since the contact is perfect from the beginning of the test. For this reason, the maximum load of the experimental curve was moved to match the peak of the simulated curve.
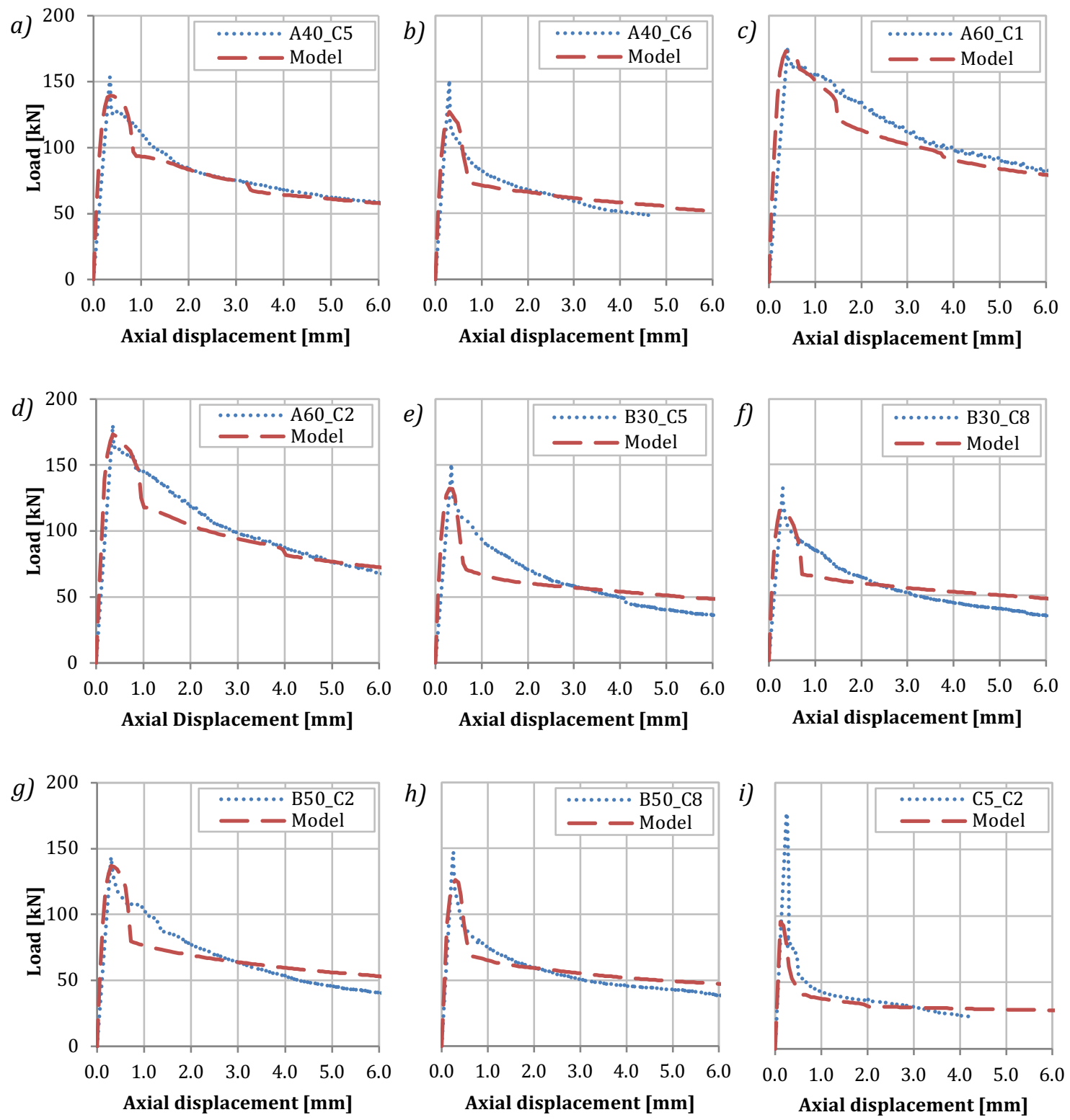

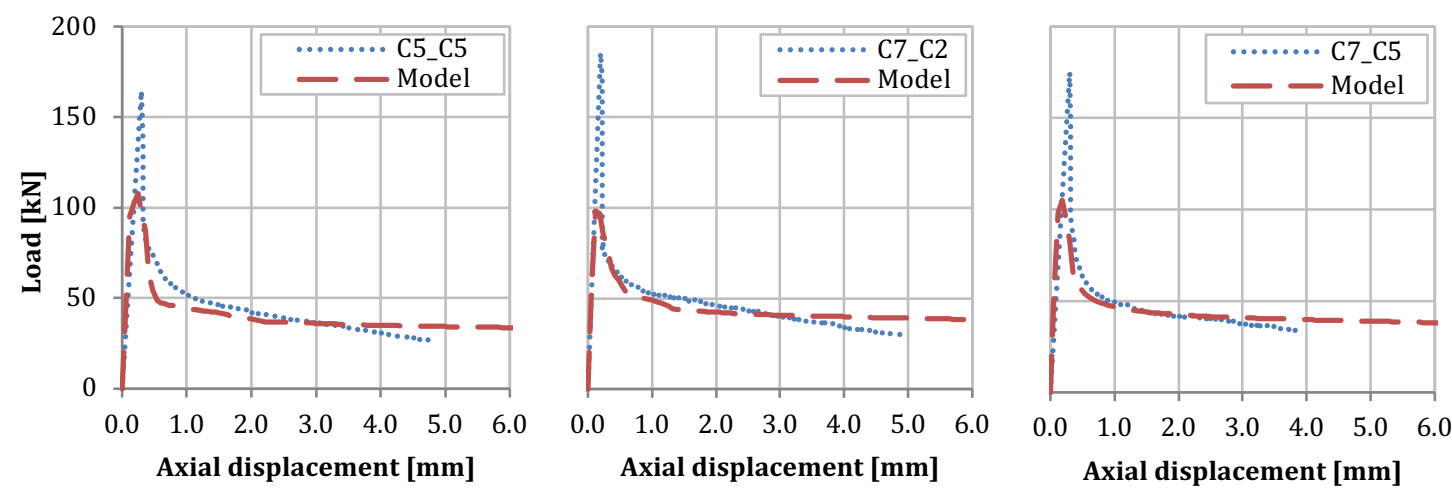

Figure 11 Experimental and numerical $P$ - $\delta$ curves for: a) $\left.\left.\left.A 40 \_C 5, b\right) A 40_{-} C 6, c\right) A 60 \_C 1, d\right) A 60 \_C 2$, e) $B 30 \_C 5$, f) $B 30 \_C 8, g$ ) B50_C2, h) B50_C8, i) C5_C2, j) C5_C5, k) C7_C2 and l) C7_C5.

A general overview of the curves reveals that the model is not able to predict the sudden drop of load after the cracking occurs. In general, the model provides a peak load close to the experimentally obtained for series $\mathrm{A}$ and $\mathrm{B}$, whereas the predicted value for series $\mathrm{C}$ is lower than the experimental value. It should be remarked that the novelty of the formulation proposed is that it is valid for the post-cracking stage and, for that reason; the aim of the finite element analysis is to validate the capacity of the model to reproduce that stage of the experimental curves.

Regarding the post-cracking stage, the results indicate that the predicted curves exhibit a tendency very similar to the one experimentally observed, especially from a displacement of $2.0 \mathrm{~mm}$ onwards. However, at the same time, a growing difference between the experimental and predicted results is detected as the displacement increases. This is particularly evident in series B30 and B50 for displacements bigger than $4.0 \mathrm{~mm}$.

In order to further analyse this behaviour, the differences in the values of load for displacements of $1.0 \mathrm{~mm}, 3.0 \mathrm{~mm}$ and $5.0 \mathrm{~mm}$ are included in Table 8 . Notice that a positive value indicates that the prediction overestimates the value of load, whereas a negative number corresponds to an underestimation of the experimental value.

Table 8. Differences between experimental and predicted load values for displacements of 1.0, 3.0 and $5.0 \mathrm{~mm}$.

\begin{tabular}{ccccc}
\hline \multirow{2}{*}{ Series } & Specimen & Differences between experimental data and model [\%] \\
& & $\mathbf{1 . 0} \mathbf{~ m m}$ & $\mathbf{3 . 0} \mathbf{~ m m}$ & $\mathbf{5 . 0} \mathbf{~ m m}$ \\
\hline \multirow{3}{*}{ A } & A40_C5 & -15.7 & 0.1 & -2.1 \\
$(\mathrm{SFRC})$ & A40_C6 & -13.2 & 4.7 & 12.5 \\
& A60_C1 & -2.1 & -7.8 & -6.6 \\
& A60_C2 & -13.8 & -3.7 & 0.0 \\
\hline \multirow{3}{*}{ B } & B30_C5 & -28.9 & -1.7 & 27.2 \\
(SFRC) & B30_C8 & -23.6 & 7.0 & 26.5 \\
& B50_C2 & -26.5 & 0.6 & 23.2 \\
& B50_C8 & -12.8 & 9.4 & - \\
& C5_C2 & -11.5 & -1.0 & - \\
C & C5_C5 & -14.4 & -1.0 & 32.0 \\
\hline
\end{tabular}

From the results, it is found that the difference between both curves is highest for a value of displacement of $1.0 \mathrm{~mm}$. It is important to highlight the difficulty that the modelling of the Barcelona test entails since, as previously introduced, after the cracking of the concrete matrix the failure is governed by a kinematic mechanism. This change in the resistant mechanism is very hard to reproduce even with advanced finite element software. In this case, the differences between the results provided by the model and the experimental data may be partially attributed to the 
difficulty to reproduce such phenomenon. Nevertheless, as the response FRC stabilizes, the experimental response and the prediction of the model become closer (around a displacement of 2.0 and $3.0 \mathrm{~mm})$.

In the last stretch of the post-cracking stage (around a displacement of $5.0 \mathrm{~mm}$ ), the difference between the model and the experimental results increases again. In fact, the overestimation at 5.0 $\mathrm{mm}$ of the models ranges from $15 \%$ to $30 \%$ for series B and C. In the case of series A, the difference remains below $20 \%$. At such advanced stage of the test, the influence of the type of fibre and the fibre content may be significant. Notice that the average difference for series B50 is lower than for series B30, which has lower fibre content than the former. This behaviour may also be observed for series $\mathrm{C}$, since the average difference is lower for $\mathrm{C} 7$ than for $\mathrm{C} 5$.

Despite the differences, the model yields results with a tendency and an absolute value similar to those from the experimental test. Taking into account the particularities in the response of FRC and the numerical difficulty to simulate the Barcelona test in a finite element model, the results indicate that the simplified constitutive equation from this work provides satisfactory results.

\section{Comparative analysis with the models in European codes}

The formulation based on the Barcelona test is compared in this section with the constitutive models in the European codes and recommendations for the design of FRC, which are based on the flexural performance of small beams. For that purpose, the trilinear/multilinear models from the DBV [31], the RILEM [32], the EHE-08 [27] and the Model Code 2010 [21] were selected since they reproduce more accurately the contribution of the fibres after cracking. In the case of the CNR-DT 204 [33], the bilinear model was considered. Even though the most recent recommendations already include certain plastic fibres as structural fibres, it should be remarked that these constitutive models are based on the experiences with steel fibre reinforcement.

The values of the parameters defining each of the constitutive models for series A40, A60, B30, B50, C5 and C7 are presented in Table 9. Notice that the tensile strength is $\sigma_{1}$ for all models except the M2010, in which the tensile strength is represented by $\sigma_{2}$ due to the shape of the diagram. Additionally, it should be pointed out that partial safety factors were not used to obtain any values of stress and strain. The notation used to refer the models in the codes is DBV, RILEM, CNR-DT, EHE and MC (or beam models as a group); while for the formulation proposed it is BCN.

Table 9. Parameters defining the constitutive models of series A40, A60, B30, B50, C5 and C7.

\begin{tabular}{|c|c|c|c|c|c|c|c|c|c|}
\hline Series & Models & $\begin{array}{c}\sigma_{1} \\
{[\mathrm{MPa}]}\end{array}$ & $\begin{array}{c}\varepsilon_{1} \\
{[\% 0]}\end{array}$ & $\begin{array}{c}\sigma_{2} \\
{[\mathrm{MPa}]}\end{array}$ & $\begin{array}{c}\mathcal{E}_{2} \\
{[\%]}\end{array}$ & $\begin{array}{c}\sigma_{3} \\
{[\mathrm{MPa}]}\end{array}$ & $\begin{array}{c}\varepsilon_{3} \\
{[\%]}\end{array}$ & $\begin{array}{c}\sigma_{4} \\
{[\mathrm{MPa}]}\end{array}$ & $\begin{array}{c}\mathcal{E}_{4} \\
{[\% 0]}\end{array}$ \\
\hline \multirow{6}{*}{ A40 } & DBV & 2.536 & 0.104 & 0.642 & 0.204 & - & - & 0.522 & 10.000 \\
\hline & RILEM & 5.907 & 0.203 & 2.811 & 0.303 & - & - & 2.451 & 25.000 \\
\hline & CNR-DT & 2.811 & 0.097 & - & - & - & - & 1.916 & 20.000 \\
\hline & EHE & 3.038 & 0.105 & 2.811 & 0.205 & - & - & 2.274 & 20.000 \\
\hline & MC & 3.089 & 0.106 & 3.432 & 0.150 & 2.806 & 0.193 & 2.274 & 20.000 \\
\hline & $\mathrm{BCN}$ & 2.851 & 0.098 & 2.191 & 0.198 & 1.447 & 4.000 & 0.907 & 20.000 \\
\hline \multirow{6}{*}{ A60 } & DBV & 3.395 & 0.107 & 1.200 & 0.207 & - & - & 0.996 & 10.000 \\
\hline & RILEM & 6.657 & 0.211 & 2.879 & 0.311 & - & - & 2.394 & 25.000 \\
\hline & CNR-DT & 2.879 & 0.091 & - & - & - & - & 1.146 & 20.000 \\
\hline & EHE & 3.423 & 0.091 & 2.879 & 0.208 & - & - & 1.839 & 20.000 \\
\hline & MC & 3.481 & 0.110 & 3.868 & 0.150 & 2.855 & 0.473 & 1.839 & 20.000 \\
\hline & BCN & 3.368 & 0.107 & 3.199 & 0.207 & 2.784 & 4.000 & 1.704 & 20.000 \\
\hline B30 & DBV & 2.918 & 0.097 & 0.040 & 0.197 &  & - & 0.000 & 6.300 \\
\hline
\end{tabular}




\begin{tabular}{|c|c|c|c|c|c|c|c|c|c|}
\hline & RILEM & 5.722 & 0.189 & 1.677 & 0.289 & - & - & 1.338 & 25.000 \\
\hline & CNR-DT & 1.677 & 0.056 & - & - & - & - & 0.884 & 20.000 \\
\hline & EHE & 2.943 & 0.097 & 1.677 & 0.197 & - & - & 1.201 & 20.000 \\
\hline & MC & 2.993 & 0.099 & 3.325 & 0.150 & 1.671 & 0.266 & 1.201 & 20.000 \\
\hline & $\mathrm{BCN}$ & 2.542 & 0.094 & 2.056 & 0.194 & 1.417 & 4.000 & 0.688 & 20.000 \\
\hline \multirow{6}{*}{ B50 } & DBV & 2.871 & 0.096 & 0.332 & 0.196 & - & - & 0.175 & 10.000 \\
\hline & RILEM & 5.629 & 0.188 & 3.860 & 0.288 & - & - & 3.284 & 25.000 \\
\hline & CNR-DT & 3.860 & 0.129 & - & - & - & - & 2.312 & 20.000 \\
\hline & EHE & 2.895 & 0.109 & 3.860 & 0.196 & - & - & 2.931 & 20.000 \\
\hline & MC & 2.944 & 0.098 & 3.271 & 0.196 & 3.143 & 16.346 & 2.931 & 20.000 \\
\hline & $\mathrm{BCN}$ & 2.724 & 0.091 & 2.439 & 0.191 & 1.629 & 4.000 & 0.803 & 20.000 \\
\hline \multirow{6}{*}{ C5 } & DBV & 3.289 & 0.105 & 0.303 & 0.205 & - & - & 0.244 & 10.000 \\
\hline & RILEM & 6.449 & 0.206 & 0.818 & 0.306 & - & - & 0.769 & 25.000 \\
\hline & CNR-DT & 0.818 & 0.026 & - & - & - & - & 0.608 & 20.000 \\
\hline & EHE & 3.748 & 0.120 & 0.818 & 0.220 & - & - & 0.692 & 20.000 \\
\hline & MC & 3.391 & 0.108 & 3.768 & 0.150 & 0.848 & 0.189 & 0.692 & 20.000 \\
\hline & $\mathrm{BCN}$ & 3.329 & 0.106 & 1.339 & 0.206 & 0.805 & 4.000 & 0.491 & 20.000 \\
\hline \multirow{6}{*}{$\mathrm{C} 7$} & DBV & 3.409 & 0.106 & 0.594 & 0.206 & - & - & 0.655 & 10.000 \\
\hline & RILEM & 6.685 & 0.208 & 1.561 & 0.308 & - & - & 1.931 & 25.000 \\
\hline & CNR-DT & 1.561 & 0.049 & - & - & - & - & 2.074 & 20.000 \\
\hline & EHE & 3.438 & 0.121 & 1.561 & 0.207 & - & - & 1.868 & 20.000 \\
\hline & MC & 3.515 & 0.110 & 3.906 & 0.150 & 1.487 & 0.180 & 1.868 & 20.000 \\
\hline & $\mathrm{BCN}$ & 3.432 & 0.107 & 1.487 & 0.207 & 0.910 & 4.000 & 0.610 & 20.000 \\
\hline
\end{tabular}

The results regarding the tensile strength $\left(\sigma_{1}\right)$ reveal that the lowest values always correspond to the DBV and the highest to the RILEM. In this analysis, the value of the CNR-DT model is not considered since it is a simplified bilinear model which cannot be compared to a trilinear model. The values provided by the BCN model remain between the limit values of the DBV and the RILEM. In fact, the value of $\sigma_{1}$ of the DBV is only $11.0 \%, 0.8 \%, 14.8 \%, 5.4 \%, 1.2 \%$ and $0.7 \%$ lower than the value of the $\mathrm{BCN}$ for series $\mathrm{A} 40, \mathrm{~A} 60, \mathrm{~B} 30, \mathrm{~B} 50, \mathrm{C} 5$ and $\mathrm{C} 7$, respectively; whereas the value of the RILEM is $107.2 \%, 97.6 \%, 125.1 \%, 106.6 \%, 93.7 \%$ and $94.8 \%$ higher than the value of BCN for A40, A60, B30, B50, C5 and C7, respectively. In general, the beam model that presents the closest values to the $\mathrm{BCN}$ is the MC (note that the tensile strength of the MC corresponds to $\sigma_{2}$ ).

The other parameters in Table 9, particularly the values of stress, may be more easily identified and analysed if plotted. In Figure 12, the constitutive models obtained from the average results of the beam tests are compared to the models determined by means of the average results of the Barcelona test for each series. In general, the highest values of correspond to the RILEM, the EHE or the MC. The BCN model ranges between the ones presenting the lowest and the highest values of residual strengths (except for series A60). The curves of series A40 are an example of such behaviour.

Figures $12 \mathrm{a}$ and $12 \mathrm{~b}$ correspond to the same type of steel fibre with a high aspect ratio $(L / d=83)$ for fibre contents of $40 \mathrm{~kg} / \mathrm{m}^{3}$ and $60 \mathrm{~kg} / \mathrm{m}^{3}$, respectively. An increase of $20 \mathrm{~kg} / \mathrm{m}^{3}$ in the fibre content leads to a significant increment in the values of stress, which is observed if the curves obtained with the BCN model for A40 and A60 are compared. In fact, the values of $\sigma_{2}, \sigma_{3}$ and $\sigma_{4}$ for A60 are $46.0 \%, 92.3 \%$ and $87.9 \%$ higher than for A40. It is reasonable that the lowest increment corresponds to $\sigma_{2}$ since after the cracking the reinforcement capacity of the fibres is not fully developed until higher values of strain, which correspond to $\sigma_{3}$. Likewise, it could be expected that the increment in the value of the ultimate stress $\left(\sigma_{4}\right)$ should be lower than for $\sigma_{3}$ due to the debonding-slipping mechanisms. 
However, such increase in the values of stress does not occur in the case of the beam models, which might be attributed to the fact that the constitutive models of series A60 were obtained with the results of only one beam (the other tests failed due to a problem with the test equipment). Therefore, conclusive remarks cannot be made from comparing the beam models of series A40 and A60; even though a significant increase in the response should be expected if more beams had been tested.

a)

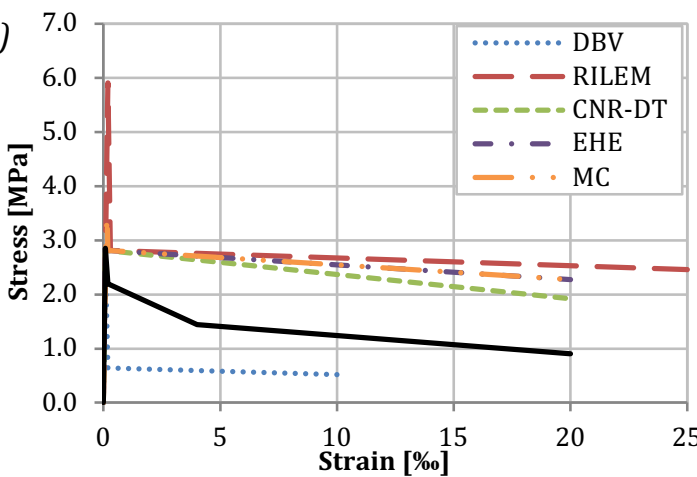

c)

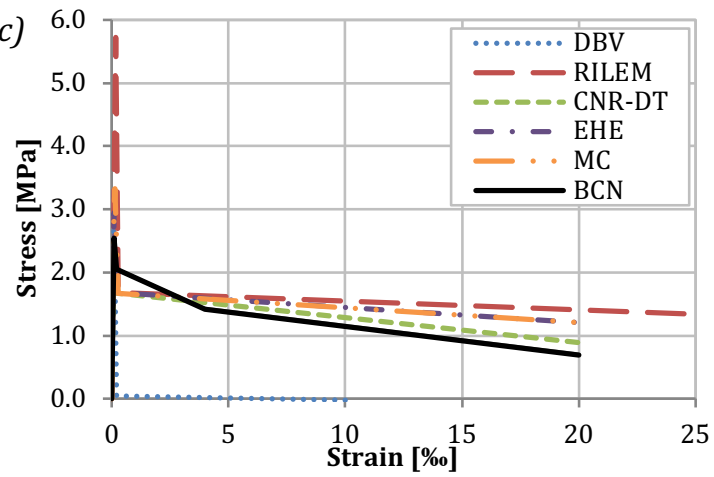

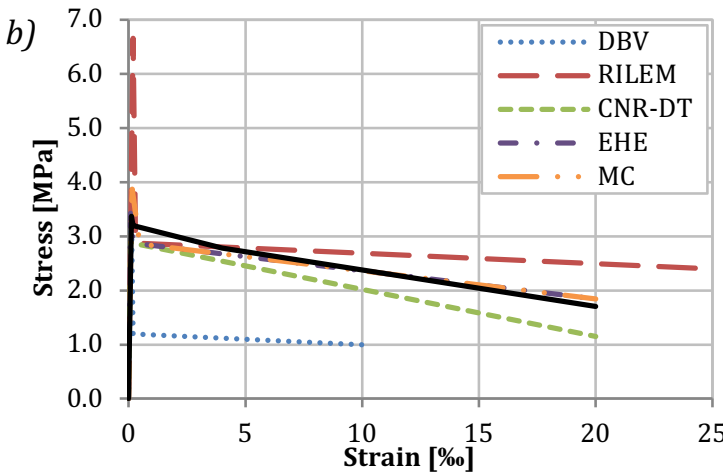

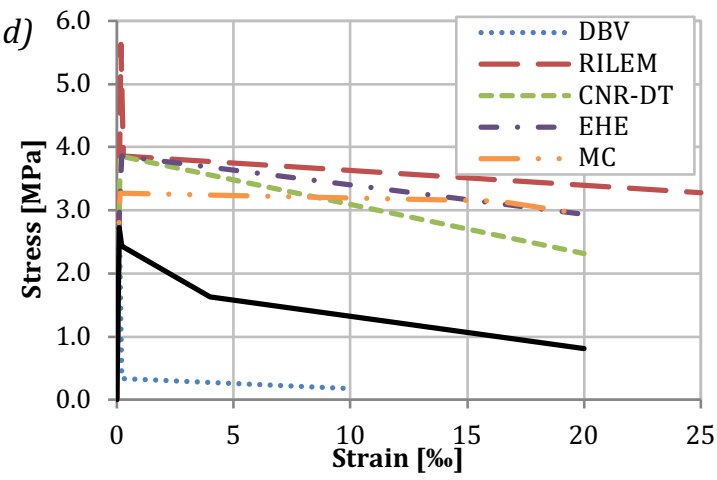



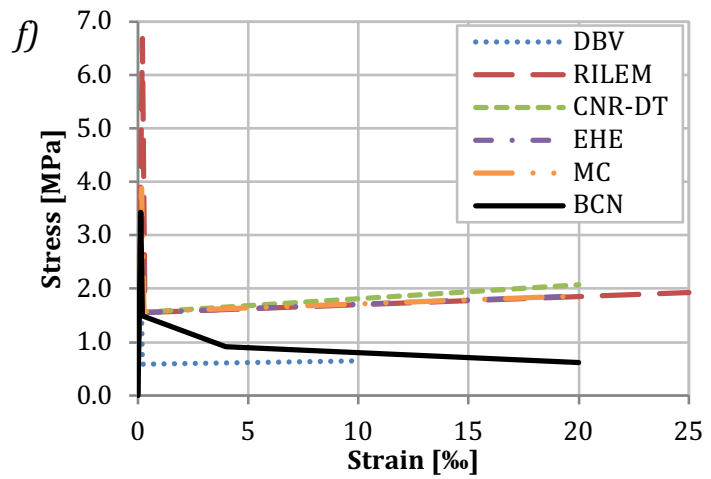

Figure 12. Comparison of the formulation based on the Barcelona test with the constitutive models based on beam tests: a) A40, b) A60, c) B30, d) B50, e) C5 and f) C7.

Regarding 12c and 12d, corresponding to series B30 and B50, a noticeable increase in the response is observed in the beam models when the amount of fibres increases from $30 \mathrm{~kg} / \mathrm{m}^{3}$ to $50 \mathrm{~kg} / \mathrm{m}^{3}$. The increase in the case of the BCN model is more subtle than for series A40 and A60; being the values of $\sigma_{2}, \sigma_{3}$ and $\sigma_{4}$ for B50 only 18.6\%, 15.0\% and 16.8\% higher than for B30. The reason for this difference between series A and B may be attributed to the type of fibre. Despite having the same length, the SF of series B has a smaller aspect ratio than the SF of series A and, consequently, the number of fibres in the concrete matrix is lower. Therefore, despite increasing the fibre content in $20 \mathrm{~kg} / \mathrm{m}^{3}$ in both cases, the number of fibres is higher for series $\mathrm{A}$, thus leading to a higher restriction of the crack opening and higher values of stress. 
From the behaviour observed in Figures $12 \mathrm{c}$ and $12 \mathrm{~d}$ a question regarding the differences between the beam models and the BCN test may be raised. Why the increase in fibre content leads to bigger increments in the stresses for the beam models? This is probably related to the amount of energy dissipated at the moment the main cracks appear and during the whole test. The study by Guàrdia [34] revealed that the energy dissipated in the Barcelona test is around 4 to 5 times bigger than in the beam test. Such difference in the amount of energy released may be attributed to the bigger crack surface in the case of the Barcelona test. Hence, an equivalent increment in the values of stress in the BCN model would require a bigger increase of the fibre content.

In the case of the plastic fibres (see Figures 12e and 12f), an increase in the fibre content of $2 \mathrm{~kg} / \mathrm{m}^{3}$ (from $0.55 \%$ to $0.77 \%$ in volume) does not result in a significant increase of the values of stress for neither the beam models nor the BCN model. However, a significant difference in the response of the beam models is observed between series C5 and C7 since the latter exhibits hardening behaviour. This phenomenon does not appear in the case of the BCN model and the reason may be found in the failure mechanism of the Barcelona test.

Failure in the Barcelona test occurs when the stress in the specimens reaches the tensile strength of concrete. At this point, two scenarios are possible: a softening behaviour or a hardening behaviour. The softening behaviour is the most common response and usually takes place for low or moderate fibre contents since the restriction to the opening of the radial cracks is small. In such case, the conical wedge would slide inside the specimen leading to a sudden reduction of the load (and energy dissipation) until the main cracks open and the fibres start their bridging mechanism. If, however, the amount of fibres is big enough, a higher restriction to the crack opening would occur as the fibres restrict the slide of the conical wedge into the specimen. This is particularly true for short fibres since their bridging capacity is activated for smaller crack openings. In this case, an increase in the load value and a hardening behaviour of the material are expected.

The same argument could be valid for the beam test. However why is it that for the same amount and type of fibres the hardening behaviour only occurs in the beam models? This is, again, related to the amount of energy dissipated when the main cracks appear and during the whole test. Given that the energy dissipated in the beam test is smaller and less abrupt than in the Barcelona test, it is possible that for the same fibre content this is high enough to result in a hardening behaviour in the bending test but still not enough to generate such response in the Barcelona test. In fact, hardening in the Barcelona test would only occur if the amount of fibres was very high and after the formation of the conical wedge the fibres did not break.

\section{Conclusions}

This paper presents a new analytical formulation to predict the post-cracking tensile behaviour of FRC from the results of the Barcelona test. It also represents a step forward on the knowledge of the failure mechanism of the Barcelona test. The analytical formulation proposed was simplified in the form of a multilinear $\sigma-\varepsilon$ diagram in which the values of strain are predefined. This simplified version of the model may be easily implemented in the current design tools and adopted by professionals.

The fracture process of the Barcelona test leads to a change of the resistant mechanism that is very hard to simulate, even with advanced FEM programs. Indeed, an approach in which the conical wedge formed during the test was geometrically predefined in the finite element analysis was required to avoid divergences. The results provided by the model were used to validate the formulation by comparing them to the experimental results of several FRC with different fibre types and contents. Despite the differences between the experimental and the predicted behaviour, 
the model provided satisfactory results with a similar trend to that of the experimental results. The numerical results revealed that the formulation is valid to estimate the post-cracking response of concrete reinforced with either steel or plastic fibres.

The development of the analytical formulation and the numerical study allowed identifying the need for reliable values of the kinetic friction coefficient for a concrete to concrete contact. Given the absence of this information in the literature, the values of the static friction coefficient provided in the design recommendations were considered as a reference.

The comparison of the model proposed with the constitutive models in European codes and guidelines revealed that the former remains in the range of stresses of the latter. On future studies, the constitutive model presented may be used to predict the response of certain structural applications to determine whether its prediction is more accurate than the beam models.

\section{Acknowledgements}

The authors of this document wish to show their gratitude for the economic support received through the Research Project BIA2010-17478: Construction processes by means of fibre reinforced concretes. The experimental program was conducted in collaboration with ESCOFET. The first and second authors acknowledge the grant FI provided by the Comissionat per a Universitats del DIUE de la Generalitat de Catalunya i del Fons Social Europeu and the support of the Departament d'Universitats, Recerca i Societat de la Informació de la Generalitat de Catalunya. The first also acknowledges the support of the Col-legi d'Enginyers de Camins, Canals i Ports de Catalunya.

\section{References}

[1] A. Blanco, P. Pujadas, A. de la Fuente, S. Cavalaro, A. Aguado, Application of constitutive models in European codes to RC-FRC. Constr. Build. Mater. 40 (2013) 246-259.

[2]P. Stroeven, Stereology of concrete reinforced with short steel fibres, Fracture Mechanics and Structural Aspects of Concrete, HERON, vol. 31 (2), Delft University of Technology, Netherlands, 1986, pp. 15-28.

[3] V.M.C.F. Cunha, J.A.O Barros, J.M Sena-Cruz, An integrated approach for modelling the tensile behaviour of steel fibre reinforced self-compacting concrete, Cem. Concr. Res. 41(1) (2011) 64-76.

[4] J. Michels, D. Waldmann, S. Maas, A. Zürbes, Steel fibers as only reinforcement for flat slab construction Experimental investigation and design, Constr. Build. Mater. 26(1) (2012) 145-155.

[5] A. Blanco, S. Cavalaro, A. de la Fuente, S. Grünewald, C.B.M Blom, J.C. Walraven, Application of FRC constitutive models to the modelling of slabs, Mater. Struct. (2014) DOI: 10.1617/s11527-014-0369-5.

[6] P. Pujadas, A. Blanco, S. Cavalaro, A. Aguado, Plastic fibres as the only reinforcement for flat suspended slabs: Experimental investigation and numerical simulation, Constr. Build. Mater. 57 (2014) 92-104.

[7] B. Parmentier, E. De Grove, L. Vandewalle, F. Van Rickstal, Dispersion of the mechanical properties of FRC investigated by different bending tests, in WalravenStoelhost. fib Symposium "Tailor Made Concrete Structures", Taylor \& Francis Group, Amsterdam, 2008, pp. 507-51.

[8] C. Molins, A. Aguado, S. Saludes, Double Punch Test to control the energy dissipation in tension of FRC (Barcelona test), Mater. Struct. 42(4) (2009) 415-425.

[9] C. Molins, A. Aguado, S. Saludes, T. García, New test to control tension properties of FRC, in Proceedings of the ECCOMAS Thematic Conference on Computational Methods in Tunnelling (EURO: TUN2007), Vienna, Austria., August 27-29 2007.

[10] AENOR. UNE 83515:2010. Hormigones con fibras. Determinación de la resistencia a fisuración, tenacidad y resistencia residual a tracción. Método Barcelona, Asociación Española de Normalización y Certificación Madrid, 2010.

[11] S.-H. Chao, N.B. Karki, J.-S. Cho, R.N. Waweru, Use of double punch test to evaluate the mechanical performance of fiber reinforced concrete, In Proceedings of the 6th International Workshop on High Performance Fiber Reinforced Cement Composites (HPFRCC 6), Ann Arbor, Michigan, June 20-22 2011, ParraMontesinos, ReinhardtNaaman Eds., 26-35.

[12] S. Carmona, A. Aguado, C. Molins, Generalization of the Barcelona test for the toughness control of FRC, Mater. Struct. 45(7) (2012) 1053-1069.

[13] P. Pujadas, A. Blanco, S. Cavalaro, A. de la Fuente, A. Aguado, New analytical model to generalize the Barcelona test using axial displacement. Journal of Civil Engineering and Management. 19(2) (2013) 259-271.

[14] P. Pujadas, A. Blanco, S. Cavalaro, A. de la Fuente, A. Aguado, Multidirectional double punch test to assess the post-cracking behaviour and fibre orientation of FRC, Constr. Build. Mater. 58 (2014) 214-224.

[15] W.F. Chen, Double punch test for tensile strength of concrete, ACI Mat. J. 67(2) (1970) 993-995.

[16] L. Bortolotti, Double-Punch Test for Tensile and Compressive Strengths in Concrete, ACI Mat. J. 85(1) (1988) 26-32. 
[17] W.F.Chen, R.L. Yuan, Tensile strength of concrete: double punch test, Journal of Structural Divisions. 106(8) (1980) 1673-1693.

[18] P. Marti, Size Effect in Double-Punch Tests on Concrete Cylinders, ACI Mat. J. 86(6) (1989) 597-601.

[19] X.X. Wei, K.T. Chau, Finite solid circular cylinders subjected to arbitrary surface load. Part II - Application to double-punch test. Int. J. Solids Struct. 37(40) (2000) 5733-5744.

[20] F. Laranjeira, C. Molins, A. Aguado, Predicting the pullout response of inclined hooked steel fibers, Cem. Concr. Res. 40(10) (2010) 1471-1487.

[21] fib. Model Code 2010, International Federation for Structural Concrete, Lausanne, 2010.

[22] CEN. EN 14651:2005 Test method for metallic fibrered concrete - Measuring the flexural tensile strength (limit of proportionality (LOP), residual), European Committee for Standardization, Brussels, 2005.

[23] A. Blanco, Characterization and modelling of SFRC elements, Doctoral Thesis, Universitat Politècnica de Catalunya-BarcelonaTech, Barcelona, 2013. http://www.tdx.cat/handle/10803/116195.

[24] A. Monsó, Análisis del comportamiento del hormigón reforzado con fibras para el ensayo Barcelona y de flexotracción, Bachelor Thesis, Universitat Politècnica de Catalunya-BarcelonaTech, Barcelona, 2011. http://upcommons.upc.edu/pfc/handle/2099.1/14264?locale=en.

[25] AENOR. UNE 83507:2004. Hormigones con fibras. Rotura por compresión., Asociación Española de Normalización y Certificación, Madrid, 2004.

[26] AENOR. UNE 83316:1996. Ensayos de hormigón. Determinación del módulo de elasticidad en compresión., Asociación Española de Normalización y Certificación, Madrid, 1996.

[27] CPH. Instrucción del Hormigón Estructural EHE-08, Ministerio de Fomento, Madrid, 2008.

[28] A. Pros, P. Díez, C. Molins, Numerical modeling of the double punch test for plain concrete, Int. J. Solids Struct. 48 (2011) 1229-1238.

[29] R. Burguers, J.C. Walraven, G.A. Plizzari, G. Tiberti, Structural Behavior of SFRC Tunnel Segments during TBM Operations, in Proceedings of the Underground Space - the 4th Dimension of Metropolises: World Tunnel Congress 2007 and 33rd ITA/AITES Annual General Assembly, Prague, Czech Republic, 2007, Barták., Hrdina., Romancov.Zlámal. Eds. Taylor \& Francis Group, 1461-1467.

[30] CEN. ENV 1992-1-1 Eurocode 2: Design of Concrete Structures - Part 1: General rules and rules for buildings, European Committe for Standardization, Brussels, 1992.

[31] DBV. Guide to Good Practice "Steel Fibre Concrete", German Society for Concrete and Construction Technology, Berlin, 2001.

[32] L. Vandewalle et al. Test and design methods for steel fibre reinforced concrete $-\sigma-\varepsilon$ Design Method-Final Recommendation, Mater. Struct. 36(8) (2003) 560-567.

[33] CNR. CNR-DT 204 /2006 Guide for the Design and Construction of Fiber-Reinforced Concrete Structures, Italian National Research Council, Rome, 2006.

[34] J. Guàrdia, Caracterització del comportament a tracció de formigó d'alta treballabilitat reforçat amb fibres d'acer mitjançant l'assaig Barcelona, Bachelor Thesis, Universitat Politècnica de Catalunya, Barcelona, 2008.

\section{Appendix A}

In this appendix, the procedure followed to propose a simplified version of the constitutive models is developed. The first stage of the curve of the constitutive model corresponds to the linear-elastic stage prior to cracking, where the concrete matrix bears the tensile stresses. The tensile strength $\left(\sigma_{1}\right)$ and its corresponding strain $\left(\varepsilon_{1}\right)$ can be calculated as indicated in expressions (Eq.A1) and (Eq.A2).

$$
\begin{gathered}
\sigma_{1}=\frac{F_{P \max }}{2 \cdot \pi \cdot A} \cdot \frac{\cos \beta-\mu_{k} \cdot \operatorname{sen} \beta}{\operatorname{sen} \beta+\mu_{k} \cdot \cos \beta} \\
\varepsilon_{1}=\frac{\sigma_{1}}{E_{c m}}
\end{gathered}
$$

The value of $\sigma_{1}$ can be easily determined by knowing the maximum load registered during the test $\left(F_{P \max }\right)$ and the values of the failure angle $(\beta)$ and the kinetic friction coefficient $\left(\mu_{k}\right)$. When the value of $\sigma_{1}$ is known, the strain $\varepsilon_{1}$ may be obtained using the modulus of elasticity $\left(E_{c m}\right)$.

Once the tensile strength of the concrete matrix is reached, cracking occurs and there is a drop of stress until the fibres start their bridging capacity, characterized by $\sigma_{2}$ and $\varepsilon_{2}$. The value of $\varepsilon_{2}$ is established following the philosophy in most European codes and guidelines which define this parameter as in equation (Eq.A3).

$$
\varepsilon_{2}=\varepsilon_{1}+0.1 \%
$$

In order to determine the value of $\sigma_{2}$, the load associated with the value of $\varepsilon_{2}$ must be known. For that, the displacement equivalent to the strain $\varepsilon_{2}$ must be calculated isolating $\Delta \delta_{p}$ in equation (Eq.19), which gives 
equation (Eq.A4). If a number of cracks equal 3, a $\beta$ equal to $0.438 \mathrm{rad}$ and a $\Delta \varepsilon$ equal to $0.1 \% 0\left(\varepsilon_{2}-\varepsilon_{1}\right.$ from equation (Eq.19) are assumed, the value $0.02 \mathrm{~mm}$ of displacement equivalent to the strain $\varepsilon_{2}$ is obtained. Notice that the $0.02 \mathrm{~mm}$ is measured from the displacement corresponding to $F_{P \max }$ onwards.

$$
\Delta \delta_{P}=\frac{\Delta \varepsilon \pi R}{n \tan \beta \sin \left(\frac{\pi}{n}\right)}=\frac{0.0001 \cdot \pi \cdot 75 \mathrm{~mm}}{3 \cdot \tan (0.436) \cdot \sin \left(\frac{\pi}{3}\right)}=0.02 \mathrm{~mm}
$$

The stress of $\sigma_{2}$ may be determined as shown in (Eq.A5) for the value of load corresponding to a displacement of $0.02 \mathrm{~mm}\left(F_{P 0.02 \mathrm{~mm}}\right)$.

$$
\sigma_{2}=\frac{F_{P 0.02 m m}}{2 \cdot \pi \cdot A} \cdot \frac{\cos \beta-\mu_{k} \cdot \operatorname{sen} \beta}{\operatorname{sen} \beta+\mu_{k} \cdot \cos \beta}
$$

The same procedure was used to estimate the values of $\sigma_{3}$ related with the strain $\varepsilon_{3}$. After analysing several experimental results, a $\varepsilon_{3}$ equal to $4.0 \%$ was chosen in order to obtain a good fit with the complete constitutive curve. This corresponds to a $\Delta \varepsilon$ of $3.9 \%$ o $\left(\varepsilon_{3}-\varepsilon_{1}=4.0 \%\right.$ - $0.1 \%$ ) , assuming that for typical concrete $\varepsilon_{1}$ should be close to $0.1 \%$ o. Substituting this value in equation (Eq.A4) gives a relative displacement $\Delta \delta_{p}$ of approximately $0.8 \mathrm{~mm}$. Therefore, the value stress $\sigma_{3}$ may be calculated as indicated in expression (26).

$$
\sigma_{3}=\frac{F_{P 0.75 m m}}{2 \cdot \pi \cdot A} \cdot \frac{\cos \beta-\mu_{k} \cdot \operatorname{sen} \beta}{\operatorname{sen} \beta+\mu_{k} \cdot \cos \beta}
$$

The value of $\varepsilon_{4}$ is assumed as $20 \%$, following the tendency observed in several instruction and codes regarding the maximum strain for the constitutive curves of FRC. Considering the same assumptions as for $\varepsilon_{3}$, the displacement associated to $20 \%$ ostimated in equation (Eq.19) is approximately $3.9 \mathrm{~mm}$ and, therefore, the value of $\sigma_{4}$ may be determined as indicated in expression (Eq.A7).

$$
\sigma_{4}=\frac{F_{P 4.00 m m}}{2 \cdot \pi \cdot A} \cdot \frac{\cos \beta-\mu_{k} \cdot \operatorname{sen} \beta}{\operatorname{sen} \beta+\mu_{k} \cdot \cos \beta}
$$

